\title{
A Polarimetric Radar Forward Operator for Model Evaluation
}

\author{
M. Pfeifer, G. C. Craig, M. Hagen, and C. Keil \\ DLR-Institute of Atmospheric Physics, Oberpfaffenhofen, Germany
}

(Manuscript received 1 June 2007, in final form 9 May 2008)

\begin{abstract}
A polarimetric radar forward operator has been developed as a tool for the systematic evaluation of microphysical parameterization schemes in high-resolution numerical weather prediction (NWP) models. The application of such a forward operator allows a direct comparison of the model simulations to polarimetric radar observations. While the comparison of observed and synthetic reflectivity gives information on the quality of quantitative precipitation forecasts, the information from the polarimetric quantities allows for a direct evaluation of the capacity of the NWP model to realistically describe the processes involved in the formation and interactions of the hydrometeors and, hence, the performance of the microphysical parameterization scheme. This information is expected to be valuable for detecting systematic model errors and hence improve model physics. This paper summarizes the technical characteristics of the synthetic polarimetric radar (SynPolRad). Different polarimetric radar quantities are computed from model forecasts using a T-matrix scattering code and ice phase hydrometeors are explicitly considered. To do so, the sensitivities of the scattering processes to the microphysical characteristics of different ice hydrometeors are investigated using sensitivity studies. Furthermore, beam propagation effects are considered, including attenuation and beam bending. The performance of SynPolRad and the consistence of the assumptions made in the derivation of the input parameters are illustrated in a case study. The resulting synthetic quantities as well as hydrometeor classification are compared with observations and are shown to be consistent with the model assumptions.
\end{abstract}

\section{Introduction}

Quantitative precipitation forecasts (QPF) have not shown significant improvements in recent years (Fritsch et al. 1998; Ebert et al. 2003), although continuous development of meteorological forecasting methods and observation systems has enhanced the quality of shortrange (up to 3 days) and medium-range (up to 10 days) weather forecast for parameters like temperature and wind. During winter, the skill of QPF is generally higher when the precipitation is mainly stratiform and associated with synoptic-scale systems, which are normally well captured by the models (Ebert et al. 2003). During the warm season, however, most of the significant precipitation events are associated with convection for which operational models tend to perform poorly (Droegemeier et al. 2000; Ebert et al. 2003). This indicates that improved short-range forecasts of precipita-

Corresponding author address: Monika Pfeifer, DLR-Institute of Atmospheric Physics, Oberpfaffenhofen, 82234 Wessling, Germany.

E-mail: monika.pfeifer@hyds.es tion require improvements in the representation of convective events in numerical weather prediction (NWP; Fritsch et al. 1998).

To provide better forecasts at the convective scale, national weather services are developing and deploying a new generation of mesoscale models operating at a horizontal resolution of only a few kilometers with the aim of explicitly resolving convection. Examples include the high-resolution version of the nonhydrostatic weather forecasting model of the consortium for smallscale modeling (COSMO-DE; Steppeler et al. 2003), the French model Application of Research to Operations in Mesoscale (AROME; Ducrocq et al. 2005), and the American Weather Research and Forecasting (WRF; Skamarock et al. 2005). Comparison studies have shown conclusively that such models performed better than single column models with a convection scheme (Bechtold et al. 2000; Guichard et al. 2004). On the other hand Bryan et al. (2003) and Craig and Dörnbrack (2008) have shown that resolutions of at least 100 $\mathrm{m}$ will be required to accurately simulate convective dynamics, so the trend to higher resolution is likely to continue. 
However, refining the grid spacing only improves QPF if the model physics, and especially the microphysical parameterizations, are adapted to the finer resolution. Microphysical parameterization schemes have been identified by a number of studies as a principal source of error. In particular the formation and distribution of precipitation has been found to be extremely dependent on the treatment of ice phase hydrometeors in the model (e.g., Ferrier et al. 1995; Gilmore et al. 2004; Colle et al. 2005; Garvert et al. 2005). Since microphysical processes such as the formation of heavily rimed ice hydrometeors (graupel and hail) feed back onto the storm dynamics, the sensitivity to microphysical parameterizations will become even more important at higher resolution where more and more detailed storm structures are simulated (Brandes et al. 2006). A realistic simulation and forecast of convection, including both intensity and life cycle, thus strongly depends on the ability of the microphysical parameterization scheme to represent the processes involved in the formation, decomposition, and interaction of the different hydrometeor types.

While high spatial resolution of NWP models is a prerequisite for an explicit description of clouds and microphysical processes, improvements in QPF will also require appropriate methods for initialization and verification that are based on observations at comparable temporal and spatial scales. Operational verification of QPF from mesoscale models is customarily based on comparisons of the model output averaged over a day with measurements from rain gauge networks (Damrath et al. 2000). Although these data provide the most reliable information on the quantitative precipitation at the ground, no information about the temporal and spatial distribution of the precipitation in the atmosphere can be given. Keil et al. (2003) showed the potential of radar observations for the evaluation of high-resolution model forecasts as radar systems provide multidimensional information at a high temporal and spatial resolution. Even more information is given by polarimetric radar, which yields enhanced data quality, better quantitative precipitation estimates, and additional information on the microphysical properties of the observed hydrometeors. Combining the information content of different polarimetric radar quantities offers the unique possibility of classifying the predominant hydrometeor type within the resolution volume (e.g., Höller et al. 1994; Vivekanandan et al. 1999; Zrnic et al. 2001). As several countries are starting to incorporate polarimetric radar technology into their radar networks [e.g., Germany, France (Gourley et al. 2006); Switzerland (Friedrich et al. 2007); the United States (Doviak et al. 2000; Ryzhkov et al. 2005)], new methods must be developed to fully exploit the information content of polarimetric radar observations to improve QPF.

Over the last few years, the potential of polarimetric radar observations for the verification and improvement of NWP models and particularly microphysical parameterization schemes has been stressed by several authors (e.g., Fritsch et al. 1998; Vivekanandan et al. 1999; Droegemeier et al. 2000; Zhang et al. 2006; Brandes et al. 2006). However, using polarimetric radar observations for model evaluation is not trivial as polarimetric radar systems do not provide explicit measurements of the quantities appearing in the microphysical equations or models themselves. In the literature, two paradigms coexist for model evaluation using observations that are not directly linked to the model parameters. Either the observations are converted into model variables (observation-to-model approach; e.g., Illingworth et al. 2007) or synthetic observables are simulated from model output by applying a so-called forward operator and performing comparisons in terms of observables (model-to-observation-approach; Chevallier and Bauer 2003). For this work, the model-toobservation approach will be used as it involves fewer assumptions and allows the full exploitation of the information content of the remote sensor. This builds on recent work describing forward operators to calculate radar reflectivities from model forecasts for evaluation purposes (Haase and Crewell 2000; Caumont et al. 2006). In contrast to the work by Keil et al. (2003) where synthetic reflectivities were derived from model forecasts using empirical formulas relating reflectivity and the rain and snow water content, radar forward operators compute the scattering processes explicitly and also consider propagation effects.

This paper presents the polarimetric radar forward operator synthetic polarimetric radar (SynPolRad; Pfeifer et al. 2004). While comparisons of synthetic and observed reflectivities allow for an evaluation of precipitation intensity, the polarimetric quantities provide further information about the microphysical properties of the precipitation and can be used to compare the spatial distribution of precipitation types employing a hydrometeor classification scheme. The polarimetric radar quantities LDR and $Z_{\mathrm{DR}}$ (e.g., Straka et al. 2000) are simulated from NWP forecasts as if operating a synthetic radar in the model domain, taking account of the main processes relevant to polarimetric radar observations. For this, SynPolRad combines a polarimetric radar model using the T-matrix approach (e.g., Waterman 1969; Barber and Yeh 1975; Bringi et al. 1986; Vivekanandan et al. 1990; Zrnic et al. 2000) with the conventional radar operator radar simulation model (RSM; Haase and Crewell 2000). 
To date, most publications studying the impact of polarimetric radar data on model skill concentrated on the liquid phase because of the relatively simple relationship between the microphysical characteristics of rain and the corresponding polarimetric quantities. Brandes et al. (2006) used polarimetric radar parameters to demonstrate the deficiencies of simple exponential parameterization schemes. Anagnostou and Krajewski (1997) and Capsoni et al. (2001) developed polarimetric radar forward operators for a statistically generated rain drop size distribution (DSD) to better understand radar observations. In contrast, SynPolRad has been developed as a novel tool for the evaluation of microphysical parameterization schemes in NWP models and, therefore, the ice phase is explicitly considered. Furthermore, SynPolRad is designed to be easily applicable to different NWP models and parameterization schemes.

For a successful evaluation of model physics, the link between the model and the forward operator has to conform as closely as possible to the model assumptions. However, in the case of polarimetric radar, not all the necessary information for the forward operator is provided by the NWP model or the microphysical parameterization scheme. These "free" parameters are mainly associated with the microphysical properties of precipitating ice hydrometeors, such as shape, density, and falling behavior, and hence the definition of reasonable parameter values requires careful attention. To do this, a large number of sensitivity tests will be used to identify the subset of parameters that make the dominant contributions to the radar signal. Additionally, the parameter ranges from a simple hydrometeor classification scheme (Höller et al. 1994) will be used to exclude unreasonable combinations of parameters, for example, a set of values that would cause a region of graupel in the model to be identified as snow. A deficiency of the model is demonstrated if the output of the simulator cannot reproduce the radar observations for any reasonable choice of the free parameters.

In the following sections, the polarimetric radar forward operator SynPolRad will be introduced. First, the individual components of SynPolRad will be discussed. These are related to the calculations of the polarimetric quantities and the simulation of the beam propagation. Next, the discussion focuses on the link between the forward operator and the NWP model. The sensitivities of polarimetric radar observables to the microphysical properties of ice will be studied on theoretical terms before deriving the free parameters. The paper finishes with a test of the consistency regarding the assumptions employed within the derivation of the free parameters. Finally, the results will be discussed and an outlook for future work will be given.

\section{The polarimetric radar forward operator SynPolRad}

The polarimetric radar operator SynPolRad simulates polarimetric radar quantities from NWP forecasts as if operating a synthetic polarimetric radar in the model domain (Fig. 1). In the first stage, the electromagnetic interactions (scattering and attenuation) of the radar beam with the hydrometeors are computed at every model grid point employing the T-matrix code of Bringi et al. (1986; see section 2a). For this, the dielectric constant of the hydrometeor must be known (section $2 \mathrm{~b}$ ). In the second stage, the propagation of the radar beam in the model domain is calculated, including beam attenuation and refraction, following Haase and Crewell (2000; section 2c). Finally, the observed and synthetic polarimetric radar quantities are interpolated onto the same coordinate system in order to allow comparisons in terms of the same physical units and the same spatial resolution (section $2 \mathrm{~d}$ ).

\section{a. Calculation of the polarimetric quantities}

In the case of linear polarization, the transmitted wave, as indicated by the electric field vector $\mathbf{E}^{i}$, as well as the scattered wave $\mathbf{E}^{s}$, can be expressed as a linear combination of two vectors in an orthonormal polarization basis. The backscattered field $\mathbf{E}^{s}$ can then be related to the incident field $\mathbf{E}^{i}$ using the backscatter matrix S (for details see Bringi et al. 1986):

$$
\left[\begin{array}{c}
E_{V}^{s} \\
E_{H}^{s}
\end{array}\right]=\mathbf{s}\left[\begin{array}{c}
E_{V}^{i} \\
E_{H}^{i}
\end{array}\right]=\left[\begin{array}{c}
S_{V V} S_{V H} \\
S_{H V} S_{H H}
\end{array}\right]\left[\begin{array}{c}
E_{V}^{i} \\
E_{H}^{i}
\end{array}\right] .
$$

The first index of the matrix elements $S_{i j}$ describes the received polarization state and the second index describes the transmitted polarization state of the waves, where $H$ gives the horizontal polarization and $V$ gives the vertical polarization. The scattering matrix $\mathbf{S}$ characterizes the microphysical properties of the scatterer relevant for the scattering process and depends on particle's size relative to wavelength, shape, orientation, and dielectric constant. Assuming a rotationally symmetric particle (horizontally or vertically aligned), the scattering matrix simplifies to $S_{i j}=S_{i j}=0$. Some types of hydrometeors falling in the atmosphere tend to tumble depending on the interactions of their shape and spatial distribution of water with the airflow. In such cases, the principal axes of the particles are not necessarily aligned horizontally or vertically. To account for this canting of the particle, $S_{V V}$ and $S_{H H}$ are changed to $S_{11}$ and $S_{22}$ denoting the principal plane backscatter matrix elements for an axisymmetric scatterer independent from the polarization basis $H$ and $V$. 


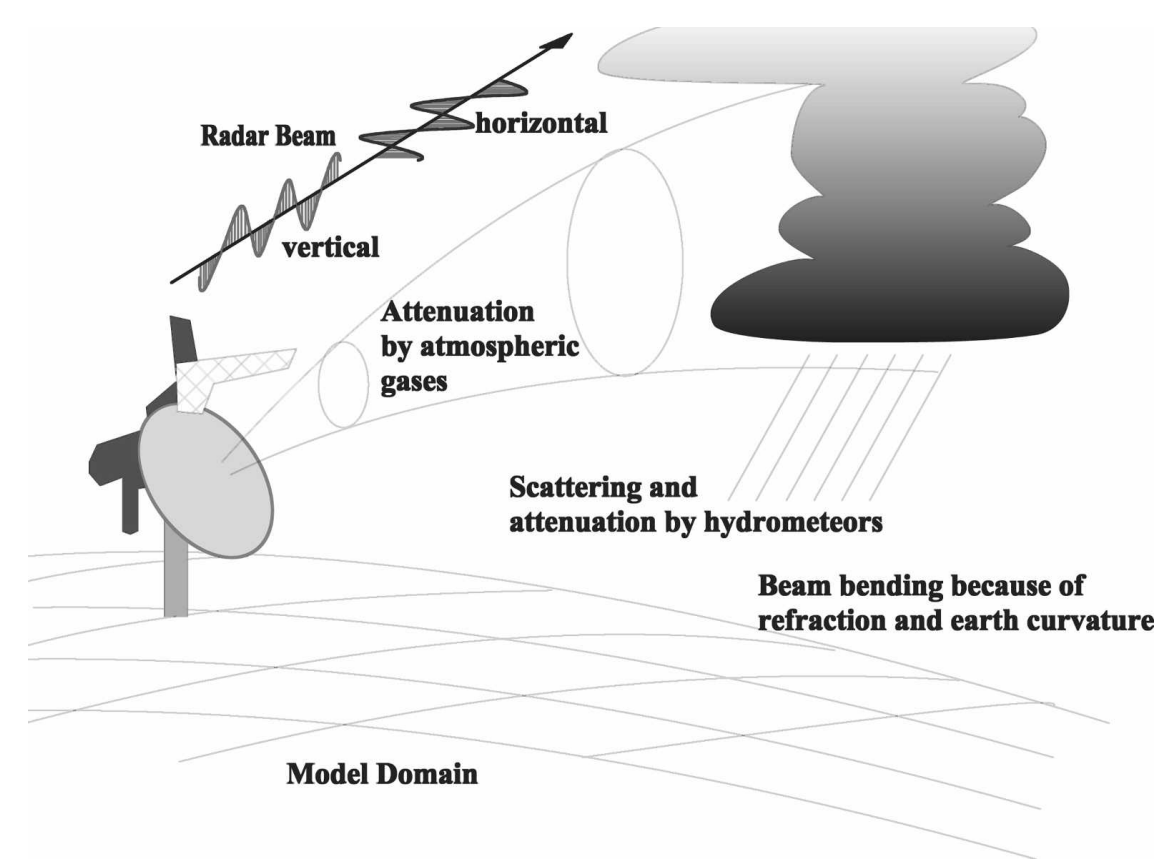

FIG. 1. Conceptual view of the physical processes represented by the polarimetric radar forward operator SynPolRad.

Polarimetric signatures also depend on the elevation angle of the radar beam and typical parameter ranges for different polarimetric radar quantities are provided by Vivekanandan et al. (1991). Within SynPolRad, this effect is not taken into account and the elevation angle is held constant for the T-matrix calculations.

The backscattered electromagnetic wave is related to the microphysical properties of the precipitation event through the radar reflectivity factor $z$. This radar reflectivity factor can be expressed for different combinations of polarizations and for an ensemble of hydrometeors with a given particle size distribution (PSD) filling the radar volume as (Holt 1984):

$$
\begin{aligned}
z_{H H}= & \frac{\lambda^{4}|K|^{2}}{\pi^{5}} \int_{D} N(D) d D \\
& \times \int_{\vartheta}\left|S_{11} \sin ^{2} \vartheta+S_{22} \cos ^{2} \vartheta\right|^{2} p(\vartheta) d \vartheta, \\
z_{V V}= & \frac{\lambda^{4}|K|^{2}}{\pi^{5}|K|^{2}} \int_{D} N(D) d D \\
& \times \int_{\vartheta}\left|S_{11} \cos ^{2} \vartheta+S_{22} \sin ^{2} \vartheta\right|^{2} p(\vartheta) d \vartheta, \quad \text { and } \\
z_{H V}= & \frac{\lambda^{4}|K|^{2}}{\pi^{5}|K|^{2}} \int_{D} N(D) d D \\
& \times \int_{\vartheta}\left|S_{11}-S_{22}\right|^{2} \cos ^{2} \vartheta \sin ^{2} \vartheta p(\vartheta) d \vartheta,
\end{aligned}
$$

where $\lambda$ is the wavelength of the radar, $|K|^{2}$ is the complex dielectric factor, $\vartheta$ is the canting angle, and $N(D)$ gives the number of hydrometeors within the diameter interval $D+d D$. Canting of the hydrometeors is accounted for by assuming a distribution (e.g., Gaussian) of canting angles $p(\vartheta)$ for the ensemble of scattering particles. Within SynPolRad, the mean canting angle is set to zero and a Gaussian distribution is specified by its standard deviation. Furthermore, the distribution is limited to a maximum canting angle. The elements of the scattering matrix $\mathbf{S}$ are calculated employing the T-matrix approximation. If the assumptions are valid, Rayleigh or Mie scattering theory are used in order to save computational time. Mixtures of different precipitation types are simulated as described in Vivekanandan et al. (1993). From $z_{H H}, z_{V V}$, and $z_{H V}$, the logarithmic radar reflectivity factor $\left[Z_{H H}=10 \log \left(\mathrm{z}_{H H}\right)\right]$, the differential reflectivity $\left[Z_{\mathrm{DR}}=10 \log \left(z_{H H} / z_{V V}\right)\right]$, and the linear depolarization ratio [LDR $=10 \log \left(z_{H V} /\right.$ $\left.z_{H H}\right)$ ] can be derived (e.g., Straka et al. 2000).

\section{b. Calculation of the complex dielectric factor}

Radar observations are highly sensitive to the complex dielectric factor, which varies significantly depending on the phase and composition of the scattering particle. For pure ice, the dielectric factor is almost a factor of 5 smaller than that of water and can be even smaller for very light ice particles such as snow (Straka et al. 2000). As ice hydrometeors normally do not consist of 
pure ice nor is the structure of the material homogeneous, the dielectric factor of hydrometeors is highly variable. These variations in dielectric factors result in significant differences in reflectivity for the same amount of precipitating water and cause prominent features such as the bright band where a sudden increase in reflectivity is observed mostly because of the enhanced dielectric factor of melting snow. Furthermore, high dielectric factors cause larger depolarization, while polarimetric signatures are reduced for low-density ice hydrometeors (Matrosov et al. 1996). In addition to the dependence on substance and phase, the complex dielectric factor depends on temperature and wavelength.

Fabry and Szyrmer (1999) found that the computed reflectivity changed significantly when different models for the dielectric factor and the snowflake density were used. The best results in comparisons with observations were obtained for a model that represented a melting snowflake with an inner core of a high-density water/ air/ice mixture and an outer low-density shell with a sharp density break in between. SynPolRad uses a simpler model where ice particles are taken to be homogeneous, as assumed in NWP models. First, dielectric factors are derived for pure ice (Warren 1984) and water (Ray 1972) at the given temperature and wavelength. Then, $K$ is calculated for the given hydrometeor, taking into account its density and degree of melting. The particle's structure is described as an air matrix with randomly oriented elliptical inclusions of ice in the case of dry particles (Bohren and Battan 1982). In the case of melting or wetted particles, the dielectric factor is calculated as water inside an ice matrix inside an air matrix, by first calculating the dielectric factor of a water and ice mixture and then, in a second step, the water/ice/air mixture.

\section{c. Beam propagation and attenuation}

SynPolRad considers beam bending due to atmospheric refraction in parameterized form assuming an effective Earth radius of $R_{\text {eff }}=4 / 3 R_{E}$, where $R_{E}$ is the actual Earth radius (Doviak and Zrnic 1984). While the knowledge of the thermodynamical profiles from the NWP model would allow for an explicit calculation of the refractive index, SynPolRad employs this propagation model in order to save computational time. The limitation of the 4/3 Earth radius approach lies in the assumption of a linear dependence of the atmosphere's refractive index on height. However, Haase and Crewell (2000) showed that differences between this approximation and a detailed calculation of the atmosphere's refractive index are only significant for elevation angles smaller than $1^{\circ}$, which will therefore not be used.
SynPolRad considers attenuation caused by atmospheric gases, clouds, and precipitation along the path of the synthetic radar beam in the model domain. While the specific attenuation $k\left(\mathrm{~dB} \mathrm{~km}^{-1}\right)$ gives the attenuation of the horizontal channel, the specific differential attenuation $A_{\mathrm{dp}}\left(\mathrm{dB} \mathrm{km}^{-1}\right)$ is defined as the difference in attenuation in the horizontal and vertical channel. Differences between the two channels result from oriented hydrometeors such as rain drops or ice crystals. Both $k$ and $A_{\mathrm{dp}}$, resulting from the presence of hydrometeors, are calculated together with the polarimetric quantities by the T-matrix module (e.g., Vivekanandan et al. 1990) solving the equations for the transmission matrix (Oguchi 1983). Gaseous attenuation due to the presence of molecular oxygen, water vapor, and nitrogen is computed employing the propagation model of Liebe et al. (1993). Total attenuation is obtained as the sum of the contributions from gaseous attenuation and attenuation due to precipitation. The attenuated polarimetric quantities can then be calculated as

$$
\begin{aligned}
Z_{H H} & =Z_{H H}^{o}-2 \int_{0}^{r} k d r, \\
Z_{\mathrm{DR}} & =Z_{\mathrm{DR}}^{o}-2 \int_{0}^{r} A_{\mathrm{dp}} d r, \text { and } \\
\mathrm{LDR} & =\mathrm{LDR}^{o}+\int_{0}^{r} A_{\mathrm{dp}} d r,
\end{aligned}
$$

where $r$ is the distance from the radar (Bringi and Chandrasekar 2001). The superscript $o$ defines the radar quantities that would have been observed without attenuation.

\section{d. Interpolation of the observations}

To simulate plan position indicator (PPI) and range height indicator (RHI) scans, SynPolRad computes first the polarimetric quantities at the grid points of the model. Then, the variables are interpolated to a polar coordinate system for the simulation of beam propagation including attenuation along its path. Finally, both the observed and the synthetic polarimetric radar data are transferred back to the model grid for evaluation. For RHI scans, the observed and simulated datasets are interpolated on a regular grid with a vertical resolution of $200 \mathrm{~m}$, because both the observations and the model data are given at an irregular vertical resolution. There are several reasons for transferring the radar data back to the model grid. First of all, successful and fair comparisons of observations and simulations are only pos- 


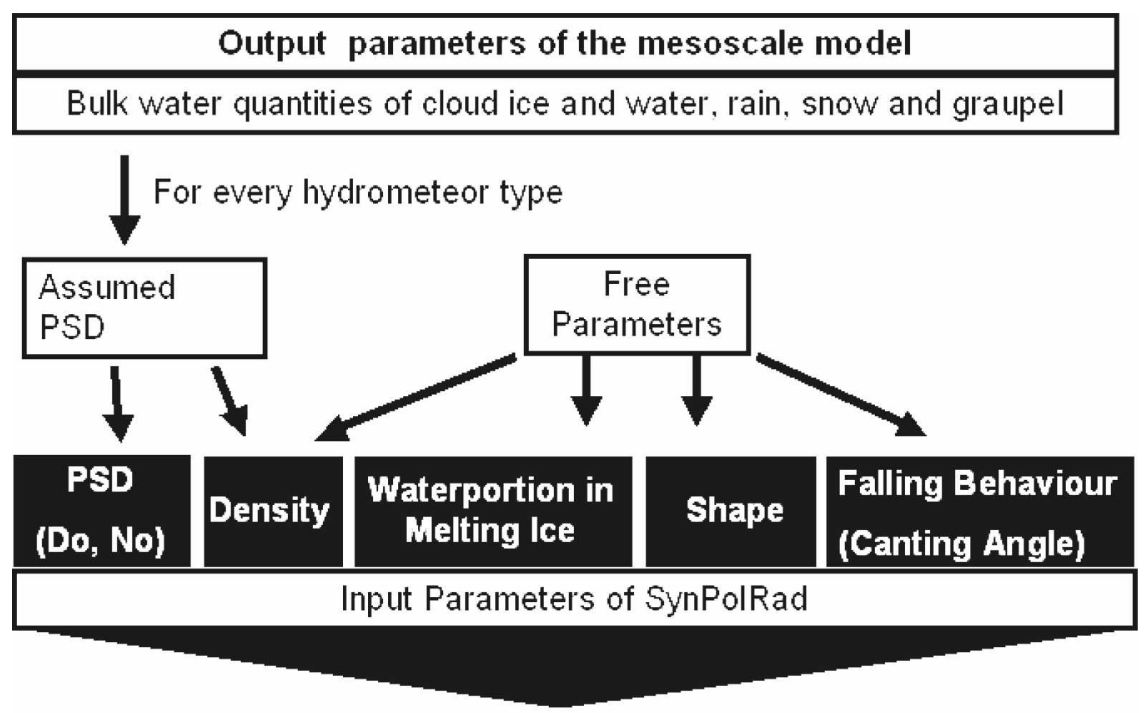

Reflectivity. LDR. ZDR

FIG. 2. Conceptual view of the link between the NWP model and the polarimetric radar forward operator SynPolRad showing the input parameters defined by the model as well as the free parameters. Density is shown as both assumed and defined by the mesoscale model, as this depends on the microphysical parameterization scheme used and the given hydrometeor type.

sible in the same spatial resolution. The resolution of the radar is finer than the model resolution, and by averaging from the finer to the coarser resolution the subgrid variability as well as extreme values of the radar measurements are smoothed. A further advantage of the model grid lies in its regular horizontal resolution, which simplifies computation of statistics since pixels have a constant area. Furthermore, calculating the polarimetric quantities at all model grid points allows the efficient computation of simulated observations for different positions of the radar in the model domain and different scan strategies. This provides the opportunity to search for the scan with the best correspondence to the observations and reduces computational costs since the expensive part of the SynPolRad simulations lies in the T-matrix calculations.

\section{Application to the NWP model}

For the computation of polarimetric radar quantities, SynPolRad requires information on the PSD, particle shapes, particle dielectric factors, and particle falling behavior, which affects the orientation of the particle relative to the direction of the incident wave and its polarization state. Most NWP models represent precipitation as bulk quantities of a given number of hydrometeor types, where microphysical properties are derived using often fixed assumptions regarding PSD and ice density. Thus there exist a number of input parameters that are neither predicted nor defined by the mesoscale model but are of significance to the simulations of polarimetric radar quantities. These are the parameters describing the shape and falling behavior of the particle as well as, in the case of ice, the degree of melting (required for determining the dielectric constant). As described in the introduction, a successful model evaluation requires that all the input variables of the forward operator should be determined by the NWP model or be derived in a model consistent way to prevent a spurious agreement with observations where deficiencies in the model are compensated by errors in the radar simulator. The link between the NWP model and SynPolRad is summarized in Fig. 2.

In the case of rain, SynPolRad can be easily applied. The DSD is specified by the microphysical parameterization scheme. The dielectric constant of water is well defined and the shape dependence can be described as a function of diameter (e.g., Andsager et al. 1999). The maximum canting angle $\vartheta$ is set to $10^{\circ}$ with a standard deviation of $5^{\circ}$ according to Chandrasekar et al. (1988) and Straka et al. (2000).

\section{a. Sensitivity of polarimetric quantities to microphysical properties of ice}

Simulation of polarimetric radar signatures from ice hydrometeors is difficult because of the natural vari- 
TABLE 1. Range of input parameters used within the sensitivity study for dry ice.

\begin{tabular}{lcc}
\hline \multicolumn{1}{c}{ Variable } & Range & Intervals \\
\hline$N_{o}\left(\mathrm{~mm}^{-1} \mathrm{~m}^{-3}\right)$ & $40-10000$ & 6 \\
$D_{o}(\mathrm{~mm})$ & $1-10$ & 10 \\
Density $\left(\mathrm{g} \mathrm{cm}^{-3}\right)$ & $0.01-0.9$ & 10 \\
Axis ratio & $0.3-3$ & 28 \\
Max canting angle $\left(^{\circ}\right)$ & $0-90$ & 10 \\
\hline
\end{tabular}

ability of density, shape, and falling behavior of the particles. To facilitate the derivation of the free parameters, the sensitivities of the polarimetric quantities to the microphysical properties of ice will be explored using sensitivity studies. The goal of this exercise is to investigate the importance of individual input parameters for the polarimetric variables and to find relations or dependencies among them that can later be used to simplify the specification of the free parameters in the full radar simulator.

The input parameters for the sensitivity study (Table 1) were chosen to represent the full range of ice phase hydrometeors in the atmosphere so that the results can be applied to any microphysical parameterization scheme. The input parameters are an exponential PSD specified by the intercept parameter $N_{o}$ and the median volume diameter $D_{o}$, the density, the axis ratio, and the maximum canting angle. Here, $D$ is the maximum spatial extension of the ice particle in contrast to the water equivalent diameter used by some authors. The values for $N_{o}$ ranged from $40 \mathrm{~mm}^{-1} \mathrm{~m}^{-3}$, the value for hail by Cheng and English (1983), through 400 $\mathrm{mm}^{-1} \mathrm{~m}^{-3}$, the lower bound for snow from Pruppacher and Klett (2003), to 800, 4000, and $8000 \mathrm{~mm}^{-1} \mathrm{~m}^{-3}$, typical intercept parameters used by microphysical parameterization schemes for snow, graupel, and rain (e.g., Steppeler et al. 2003), to finally $10000 \mathrm{~mm}^{-1} \mathrm{~m}^{-3}$, the upper bound for small hail and graupel given by Straka et al. (2000). The $D_{o}$ and density covered typical values for ice particles ranging from aggregates to heavily rimed ice including hail. The axis ratio was varied from 0.3 to 3 where 1 describes a spherical shape, axis ratios smaller than 1 oblate particles, and larger than 1 prolate particles. Smaller axis ratios are not considered because of the T-matrix method becoming numerically unstable (Mishchenko and Travis 1998). The maximum canting angle was varied from $0^{\circ}$ to $90^{\circ}$ and its standard deviation was fixed at half its value. Using database operations, sets of all possible combinations of parameters were created and used as input for the T-matrix calculations. The calculations assumed a Cband radar at a wavelength of $5.45 \mathrm{~cm}$, following the technical specifications of the Deutsches Zentrum für
Luft und Raumfahrt (DLR) polarimetric Doppler radar (POLDIRAD; Schroth et al. 1988). The temperature was held fixed at $-10^{\circ} \mathrm{C}$. The results of the sensitivity study are summarized in Figs. 3 and 4. Shown are the average, minimum, and maximum values for reflectivity, LDR, and $Z_{\mathrm{DR}}$ as functions of the input parameters of the sensitivity study. These figures combine all simulations apart from LDR where only values greater than $-100 \mathrm{~dB}$ are taken into account. In the following, the results are discussed separately for each input parameter of the sensitivity study.

The first row of Fig. 3 displays reflectivity, LDR, and $Z_{\mathrm{DR}}$ as functions of $N_{o}$. While reflectivity increases with $N_{o}$, especially for the smaller values, LDR and $Z_{\mathrm{DR}}$ remain constant over the entire range of $N_{o}$. This is not only true for the averages of the polarimetric radar quantities, but also for the minima and maxima, indicating that both quantities are independent of $N_{o}$. The negative bias of mean $Z_{\mathrm{DR}}$ is due to the larger range of axis ratios greater than 1 . Similar results are found for $D_{o}$. Reflectivity exhibits a strong dependence on $D_{o}$ while the values of LDR remain almost constant. Here $Z_{\mathrm{DR}}$ shows a slight dependence on $D_{o}$ with more extreme values for larger particle dimensions, although not to the same extent as reflectivity. In contrast to the polarimetric quantities, reflectivity is not affected by changes of $\vartheta$; LDR increases significantly with $\vartheta$ reaching maximum values at $60^{\circ}$. Furthermore, a minimum $\vartheta$ of $10^{\circ}$ is needed to produce physically significant values. While LDR is a measure for the depolarization and, therefore, sensitive to particles canted to the polarization axis, $Z_{\mathrm{DR}}$ is a measure for particles aligned parallel to the polarization axis. Accordingly, maximum positive and negative values of $Z_{\mathrm{DR}}$ are found for small canting angles. All three radar quantities show a dependence on the axis ratio of the scattering particle. In contrast to the dependence on the PSD, reflectivity exhibits a relatively small sensitivity to the axis ratio (Fig. 4). The remaining sensitivity of reflectivity is due to the fact that, for a given diameter, particles with a smaller axis ratio do not fill the radar beam as well as spherical particles with the same diameter and, therefore, deviations from spherical shape decrease reflectivity. Both LDR and $Z_{\mathrm{DR}}$ show large variations, with minimum values for both quantities in the case of spherical particles. The LDR increases strongly as the axis ratio deviates from unity. The average of $Z_{\mathrm{DR}}$ is zero for spherical particles and increases with decreasing axis ratio (oblate particles), while it decreases for prolate particles. Minimum values of $Z_{\mathrm{DR}}$ are attained for spherical values or nonspherical particles strongly canted to the polarization axis. This explains the vertical line at $0 \mathrm{~dB}$ representing the maximum $Z_{\mathrm{DR}}$ for 

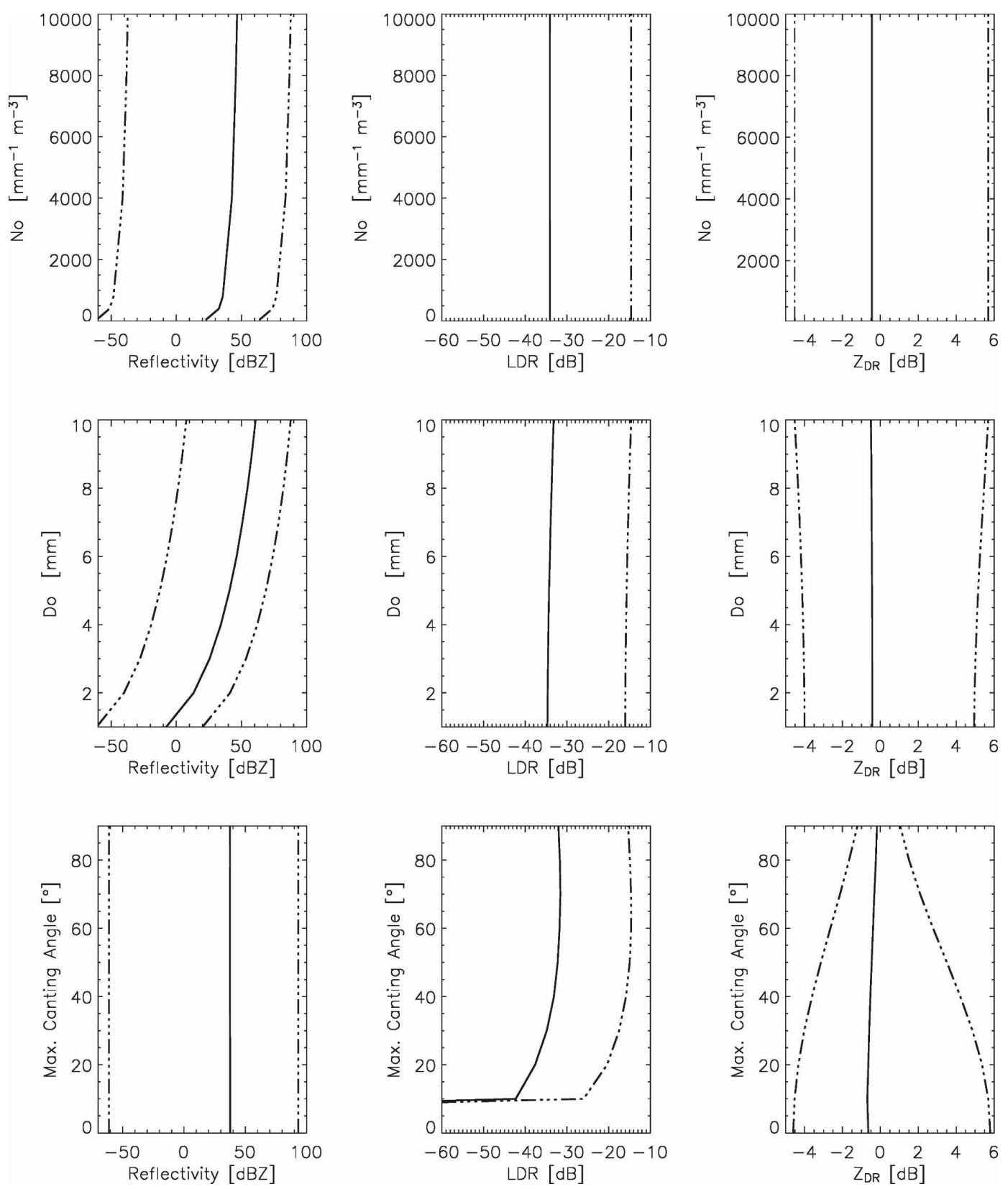

FIG. 3. (left) Reflectivity (dBZ), (middle) LDR (dB), and (right) $Z_{\mathrm{DR}}(\mathrm{dB})$ as a function of the (top) intercept parameter $N_{o}\left(\mathrm{~mm}^{-1} \mathrm{~m}^{-3}\right)$, (middle) the median volume diameter $D_{o}(\mathrm{~mm})$, and the (bottom) maximum canting angle $\left({ }^{\circ}\right)$. Each subfigure shows the average value (solid line) and the minimum and maximum value (dashed lines) of the polarimetric radar quantities from all realizations of the sensitivity study valid for the given parameter range.

prolate particles and the minimum $Z_{\mathrm{DR}}$ for oblate particles. Finally, the dependence of the radar quantities on ice density is shown assuming dry particles. All quantities exhibit a similar dependence with increasing values for increasing ice density.

To study the impact of varying dielectric constant due to variations in the ice density and the water con- tent of wet ice particles, a further sensitivity study was performed. The density of ice was varied with the same range of parameters as in the previous sensitivity study and the water content of the ice particle was varied from $0 \%$ to $100 \%$ in intervals of $10 \%$. The other parameters were fixed at $N_{o}=800 \mathrm{~mm}^{-1} \mathrm{~m}^{-3}, D_{o}=5$ $\mathrm{mm}, \vartheta=40^{\circ}$, and an axis ratio of 0.3 . Figure 5 shows 

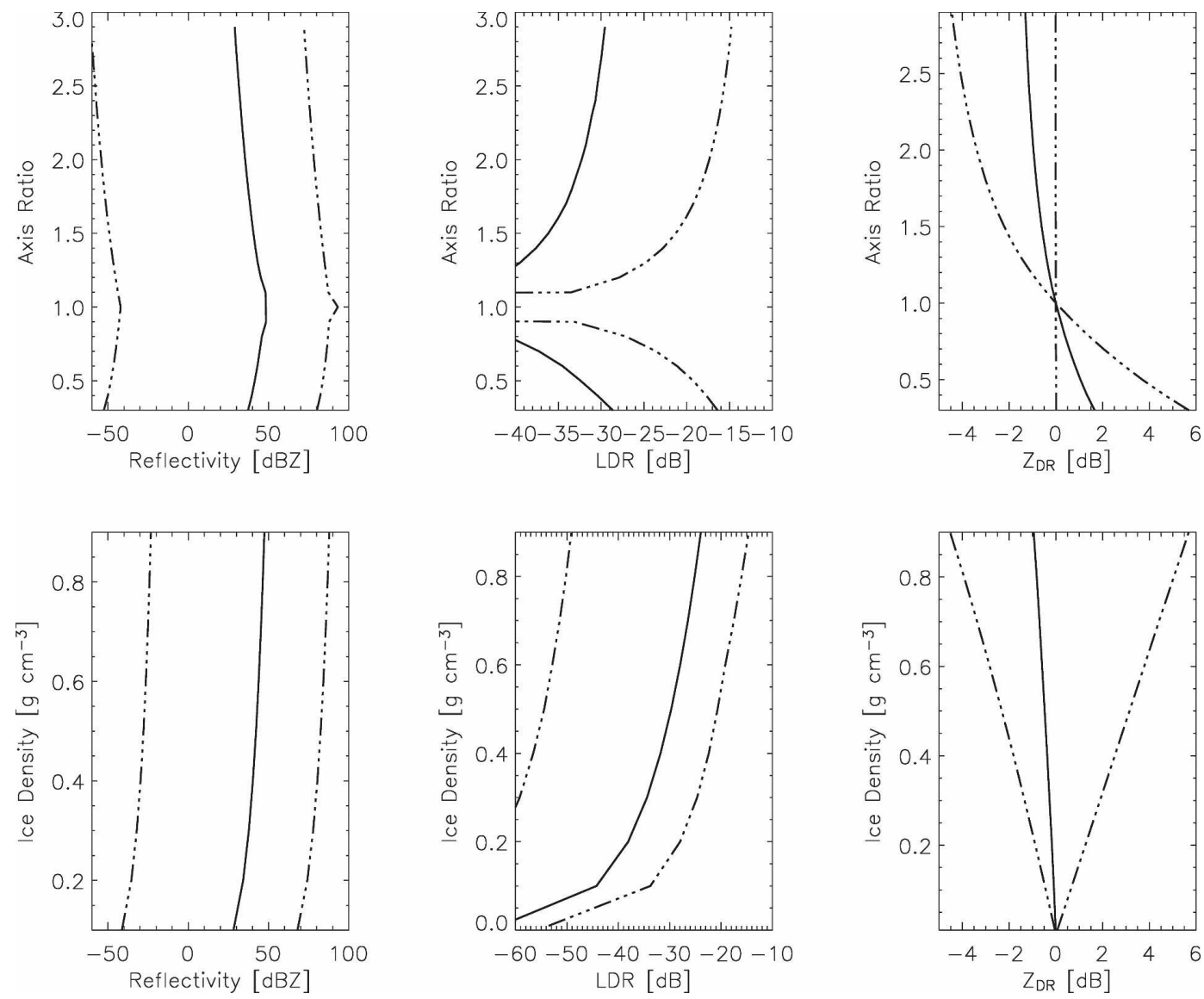

FIG. 4. Columns as in Fig. 3, but as a function of (top) the axis ratio and (bottom) the ice density $\left(\mathrm{g} \mathrm{cm}^{-3}\right)$. Each panel shows the average value (solid line) and the minimum and maximum value (dashed lines) of the polarimetric radar quantities from all realizations of the sensitivity study valid for the given parameter range.

reflectivity, LDR, and $Z_{\mathrm{DR}}$ as functions of ice density and water content. All three parameters strongly increase with density and water portion where the increase with water portion is more important than the increase with density. Furthermore, for a given density, all three quantities reach a point of saturation beyond which increasing water amount has no effect. This is due to the calculation of the dielectric constant, where for a given density inclusions of air are changed to inclusions of water to achieve the specified total water portion in the particle. At the moment where all air inclusions are filled with water, the dielectric constant does not change any more. This stage is obviously reached earlier for higher densities with fewer air inclusions. Since such high water contents are not used in SynPolRad this effect is of no further importance.

To summarize the sensitivity studies, reflectivity mainly depends on the PSD and the dielectric constant, which is a function of the density and degree of melting of the ice particle. On the other hand, reflectivity is almost unaffected by varying axis ratio and canting angle. The only effect is that extremely oblate and tumbling particles appear to be smaller in the radar beam giving a slight decrease in reflectivity for the same PSD in comparison to spherical particles. The sensitivity study showed further that the polarimetric variables LDR and $Z_{\mathrm{DR}}$ depend mainly on the axis ratio and the canting angle but vary little with $D_{o}$ or $N_{o}$. This comes about because the axis ratio is taken to be independent of diameter for ice hydrometeors (in contrast to rain). Like reflectivity, the polarimetric variables show a strong dependence on dielectric constant. Both LDR and $Z_{\mathrm{DR}}$ increase with increasing ice density, water portion in melting ice, and deviations from spherical shape. The $Z_{\mathrm{DR}}$ is greatest for nonspherical hydrometeors aligned parallel to the polarization axis, whereas LDR is greatest for nonspherical hydrometeors aligned at an angle of $45^{\circ}$. The results of the sensitivity study are independent of the meteorological conditions apart from the calculation of the dielectric constant, which features a slight temperature dependence. This temperature dependence is more important for the imagi- 

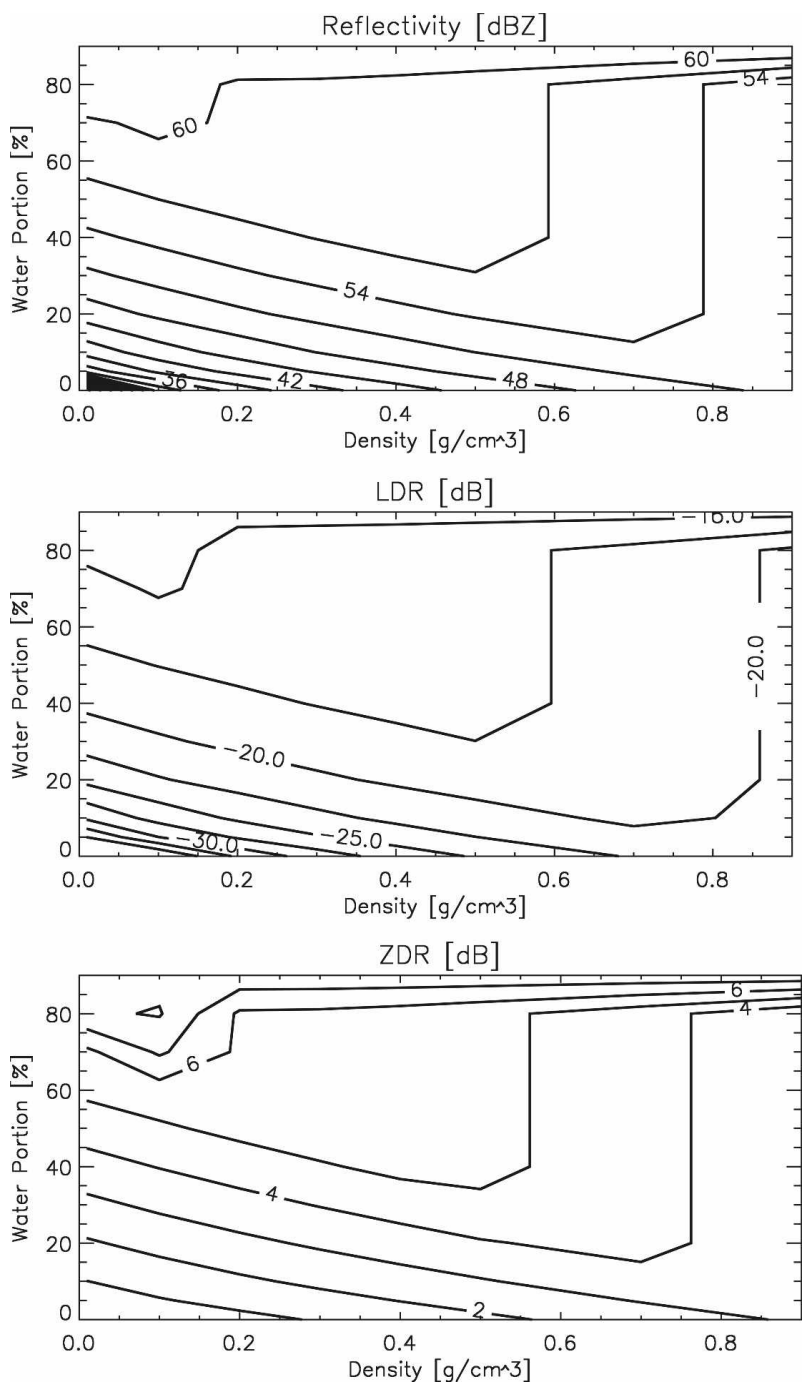

FIG. 5. Similar to Fig. 3, but as a function of density $\left(\mathrm{g} \mathrm{cm}^{-3}\right)$ and water portion (\%) in melting ice for $N_{o}=800 \mathrm{~mm}^{-1} \mathrm{~m}^{-3}$, $D_{o}=5 \mathrm{~mm}, \vartheta=40^{\circ}$, and $\alpha=0.3$.

nary part of the complex dielectric constant, describing absorption by the hydrometeor, than for the scattering processes. Since the sensitivity study has concentrated on the backscatter cross section of hydrometeors, the results will not be significantly influenced by the fixed temperature assumption.

\section{b. Determination of the free parameters for ice}

The free parameters for ice will be derived by combining the results from the sensitivity study with the information provided by the NWP model and the respective microphysical parameterization (and are thus dependent on the particular model being considered). An additional constraint will be provided by specification of typical thresholds for the polarimetric quantities
LDR and $Z_{\mathrm{DR}}$ for different hydrometeor types from a hydrometeor classification scheme (Höller et al. 1994). The sensitivity study showed that the polarimetric quantities LDR and $Z_{\mathrm{DR}}$ depend on the dielectric constant, the shape, and the falling behavior of the particle. The particle spectrum only influences on $Z_{\mathrm{DR}}$ in the case of large particle diameters. Assuming that snow and graupel particles are dry, the dielectric constant is only a function of ice density, which is defined by the NWP model. Assuming further that the axis ratio of a given hydrometeor type is constant and does not vary with diameter, a pair of fixed values for the axis ratio and $\vartheta$ can be defined such that the resulting values of synthetic LDR and $Z_{\mathrm{DR}}$ will always range within the thresholds of the hydrometeor classification. Thus, for every ice hydrometeor type, the free parameters can be defined such that the resulting synthetic polarimetric parameters will always match the hydrometeor classification, independent of the amount of the bulk water quantity or the surrounding meteorological conditions. This is possible because the hydrometeor classification scheme is based only on LDR and $Z_{\mathrm{DR}}$, which, for the given assumptions, are independent of the PSD and, therefore, the strength of the precipitation event.

In the following, the specification of the free parameters of graupel will be discussed for the COSMO-DE for illustration. The COSMO-DE is the high-resolution version of the nonhydrostatic weather forecasting model of the COSMO community presently operational at several European weather services (Steppeler et al. 2003). Precipitation processes are explicitly described using a bulk-type cloud microphysics scheme containing five prognostic hydrometeor types (cloud water, cloud ice, rain, snow, and graupel). No parameterization of deep convection is used. Graupel is described as an ice hydrometeor with a fixed density of 0.2 $\mathrm{g} \mathrm{cm}^{-3}$ corresponding to the so-called lump graupel type (e.g., Heymsfield 1978). Extracting from the database all simulations performed for this prescribed density gives the range of $L D R$ and $Z_{\mathrm{DR}}$ values that a graupel particle can assume according to the COSMODE specifications. Figure 6 shows the hydrometeor classification derived from the simulated values of LDR and $Z_{\mathrm{DR}}$ as a function of axis ratio and $\vartheta$ for the given graupel density. The phase space is dominated by a classification as snow distributed almost symmetrically around the axis ratio 1 describing spherical particles. With increasing $v$ and decreasing sphericity, the probability of a classification as graupel increases. There exists a region in the phase space (e.g., at an axis ratio of 0.6 and $\vartheta$ larger than $50^{\circ}$ ) where both classifications, snow or graupel, occur within all the realizations of the sensitivity study, due the variations of $Z_{\mathrm{DR}}$ with chang- 


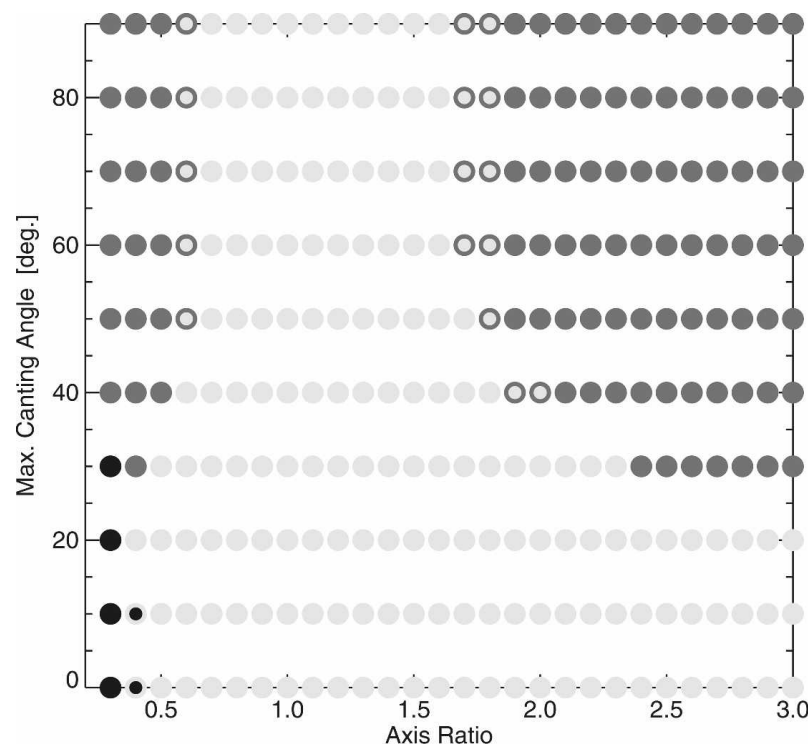

FIG. 6. Classification of hydrometeors as a function of axis ratio and maximum canting angle for a fixed density of $\rho=0.2 \mathrm{~g} \mathrm{~cm}^{-3}$. Black designates the phase space of large rain drops, dark gray stands for graupel, and light gray for snow. Combinations of axis ratio and maximum canting angle resulting in an ambiguous classification are shown in the corresponding two colors.

ing $D_{o}$. However, for axis ratios smaller than 0.6 and $\vartheta$ larger than 0.4 (or, e.g., axis ratios larger than 2.1 and $\vartheta$ larger than $40^{\circ}$ ) a classification as graupel is unambiguous. Furthermore, for very oblate particles and small maximum canting angles, particles are classified as "large raindrops" because of the enhanced values of $Z_{\mathrm{DR}}$.

Consistent with the above constraints, an axis ratio of 0.5 and a $\vartheta$ of $40^{\circ}$ (similar to the $45^{\circ}$ used by Vivekanandan 1986) were chosen for graupel, in accordance with the observations of lump graupel having typically axis ratios smaller than 1 (Heymsfield 1978). The free parameters for snow were derived in the same way. The input parameters for SynPolRad simulations using COSMO-DE output are summarized in Table 2.

\section{c. Melting ice and brightband effects}

The effects of melting or wet particles are of major importance to radar observations because of the increase in the dielectric constant and the corresponding dramatic increase in reflectivity. This effect has been investigated in a number of studies coupling a melting model to a cloud model and simulating reflectivity profiles (e.g., Klaassen 1988; Szyrmer and Zawadzki 1999; Fabry and Szyrmer 1999; Olson et al. 2001). In contrast to these detailed process studies, NWP models describe melting more crudely as a transition from snow to rain
TABLE 2. SynPolRad input parameters for the computation of synthetic polarimetric quantities from COSMO-DE forecasts. The particle size distribution $\left[N(D), N_{o}, \lambda\right]$ is predefined by the NWP model COSMO-DE (Steppeler et al. 2003).

\begin{tabular}{|c|c|c|c|}
\hline & Rain & Snow & Graupel \\
\hline$N(D)$ & & $N_{o} \exp (-\lambda D)$ & \\
\hline $\begin{array}{c}N_{o}\left(\mathrm{~mm}^{-1}\right. \\
\left.\mathrm{m}^{-3}\right)\end{array}$ & 8000 & 800 & 4000 \\
\hline$\lambda$ & {$\left[\pi \rho_{w} N_{o} /\left(\rho q_{r}\right)\right]^{1 / 4}$} & {$\left[\pi \rho_{s} N_{o} /\left(\rho q_{s}\right)\right]^{1 / 3}$} & {$\left[\pi \rho_{g} N_{o} /\left(\rho q_{g}\right)\right]^{1 / 4}$} \\
\hline Axis ratio & $f(D)$ & 0.3 & 0.5 \\
\hline $\begin{array}{l}\text { Max canting } \\
\text { angle }\end{array}$ & $10^{\circ}$ & $20^{\circ}$ & $40^{\circ}$ \\
\hline$\Delta \vartheta$ & $5^{\circ}$ & $10^{\circ}$ & $20^{\circ}$ \\
\hline \multicolumn{4}{|l|}{ Bright band } \\
\hline $\begin{array}{l}\text { Water portion } \\
(\%)\end{array}$ & & 36 & 36 \\
\hline $\begin{array}{l}\text { Max canting } \\
\text { angle }\end{array}$ & & $60^{\circ}$ & $60^{\circ}$ \\
\hline$\Delta \vartheta$ & & $45^{\circ}$ & $40^{\circ}$ \\
\hline
\end{tabular}

with coexisting snow and rain phase. This means that no extra hydrometeor class for melting snow is included and that the assumed PSD of snow is unchanged below the $0^{\circ} \mathrm{C}$ isotherm. For simulation of brightband signatures, SynPolRad changes the free parameters in order to reach the typical LDR values of $-15 \mathrm{~dB}$ (Illingworth 2004) resulting from the enhanced tumbling of melting particles. These LDR values can be attained by decreasing the axis ratio, increasing the canting angle, and/or increasing the water content of the ice hydrometeor. Decreasing the axis ratio would contradict observations where Fujiyoshi (1986) found that the axis ratio of melting snow increases toward a lens shape. Therefore, only the water content and the parameters specifying the distribution of canting angles are adapted to melting ice particles and another sensitivity study was carried out to study the resulting effects. The range of input parameters of this sensitivity study is given in Table 3.

Figure 7 shows LDR as a function of $\vartheta$ and its standard deviation $\Delta \vartheta$ and LDR as a function of water portion and $\vartheta$. Because LDR is a measure of depolarization, it is maximum when most of the hydrometeors

TABLE 3. Range of input parameters used within the sensitivity study for melting ice hydrometeors.

\begin{tabular}{lcc}
\hline \hline \multicolumn{1}{c}{ Variable } & Range & Intervals \\
\hline$N_{o}\left(\mathrm{~mm}^{-1} \mathrm{~m}^{-3}\right)$ & 800 & 1 \\
$D_{o}(\mathrm{~mm})$ & $1-8$ & 7 \\
Density $\left(\mathrm{g} \mathrm{cm}^{-3}\right)$ & 0.2 & 1 \\
Axis ratio & 0.3 & 1 \\
Max canting angle $\left(^{\circ}\right)$ & $0-90$ & 10 \\
$\Delta \vartheta\left(^{\circ}\right)$ & $10-45$ & 5 \\
Water portion $(\%)$ & $10-40$ & 16 \\
\hline
\end{tabular}



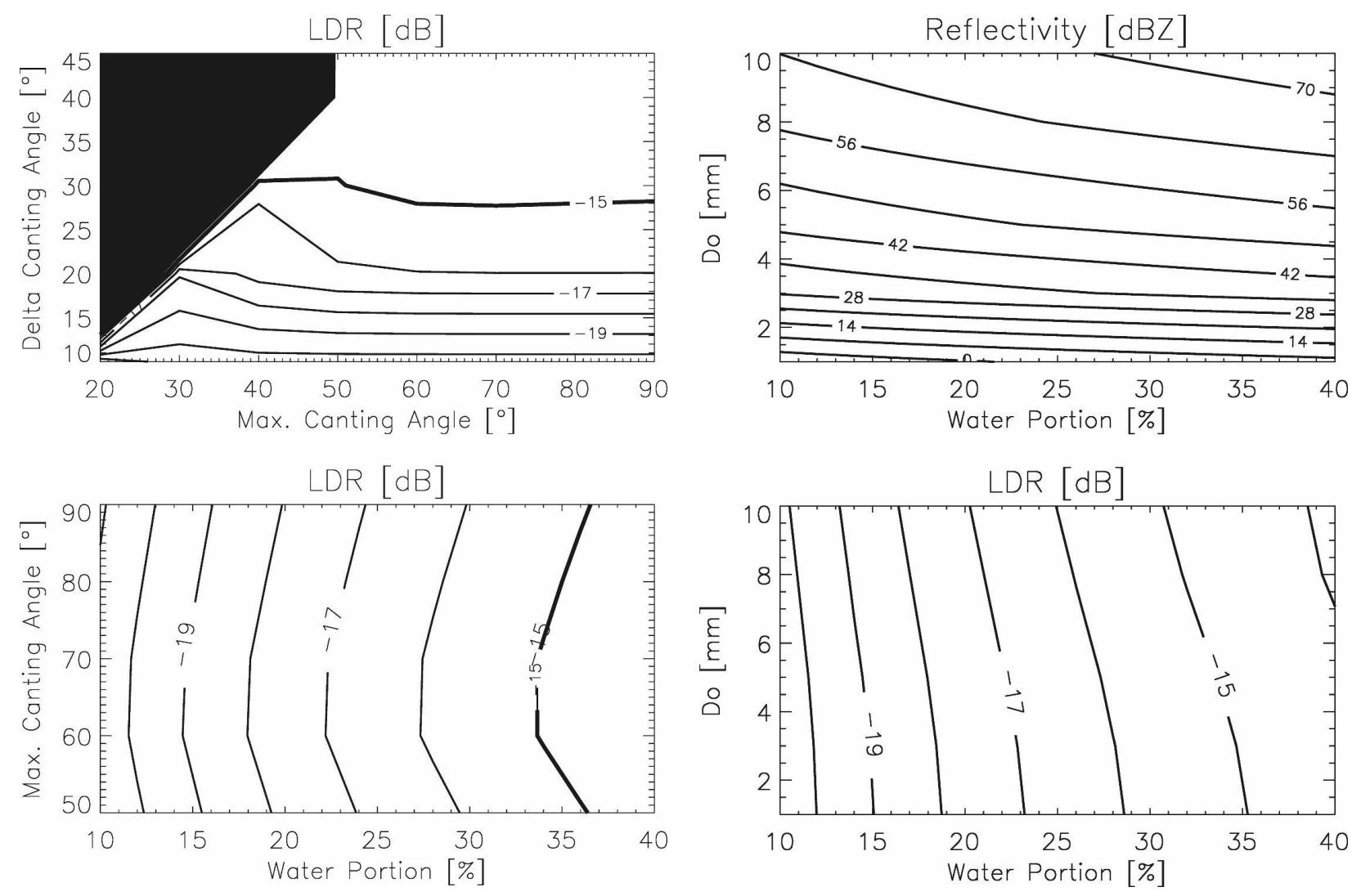

FIG. 7. (top) LDR (dB) as a function of the maximum canting angle $\vartheta$ and its standard deviation $\Delta \vartheta$ for a fixed water portion of $40 \%$. Combinations of $\Delta \vartheta$ larger than the maximum canting angle $\vartheta$ are not defined and are given in black. (bottom) LDR (dB) as a function of maximum canting angle $\vartheta$ and the water portion (\%) in melting ice. The chosen threshold of $-15 \mathrm{~dB}$ LDR is given as a thick line.

of the ensemble are aligned at or near a canting angle of $45^{\circ}$. This is achieved for $\vartheta$ in the range of $60^{\circ}-70^{\circ}$ and $\Delta \vartheta=45^{\circ}$. Furthermore, LDR increases with the water portion and maximum values are reached for a given water portion for $\vartheta$ within the same range of $60^{\circ}-70^{\circ}$. Therefore, in the future, the combination of $\vartheta=60^{\circ}$ and $\Delta \vartheta=45^{\circ}$ will be used to maximize LDR in the region of the melting layer.

Figure 8 shows reflectivity and LDR as a function of $D_{o}$ and the water fraction in melting ice. Both $Z_{H H}$ and LDR increase significantly with the water fraction of the melting snow particle while LDR is almost independent of $D_{o}$ in contrast to reflectivity. To reach values of LDR up to $-15 \mathrm{~dB}$, the water fraction must be at least $36 \%$. At the same time, it should be chosen as small as possible in order to avoid unnatural high values of reflectivity. These high values of reflectivity can occur because the PSD of snow as assumed by COSMO$\mathrm{DE}$ does not account for melting processes such as

FIG. 8. Reflectivity (dBZ) and LDR (dB) as a function of the median volume diameter $(\mathrm{mm})$ and the water portion $(\%)$ of melting ice.

break up and, therefore, large particles contribute strongly to reflectivity without affecting LDR. This is also the reason for choosing a $\vartheta$ of $60^{\circ}$ that might be larger than expected in nature.

\section{Testing SynPolRad}

In the following, the performance of SynPolRad and the assumptions regarding the free parameters of the single hydrometeor types will be tested for a case study. This is done for a squall line crossing Germany on 12 August 2004 employing a COSMO-DE forecast. In the present study the COSMO-DE model domain encompasses upper Bavaria $(100 \times 100$ grid points and 40 vertical levels) with a horizontal resolution of $2.8 \mathrm{~km}$. The high-resolution model is driven with operational hourly COSMO-EU forecasts and the simulations started at 0000 UTC. Figure 9 shows observed and synthetic $1^{\circ}$ PPI scans to give a general impression of model performance. The position and intensity of the squall line is well captured by the model but the trailing stratiform precipitation is clearly underestimated. For 

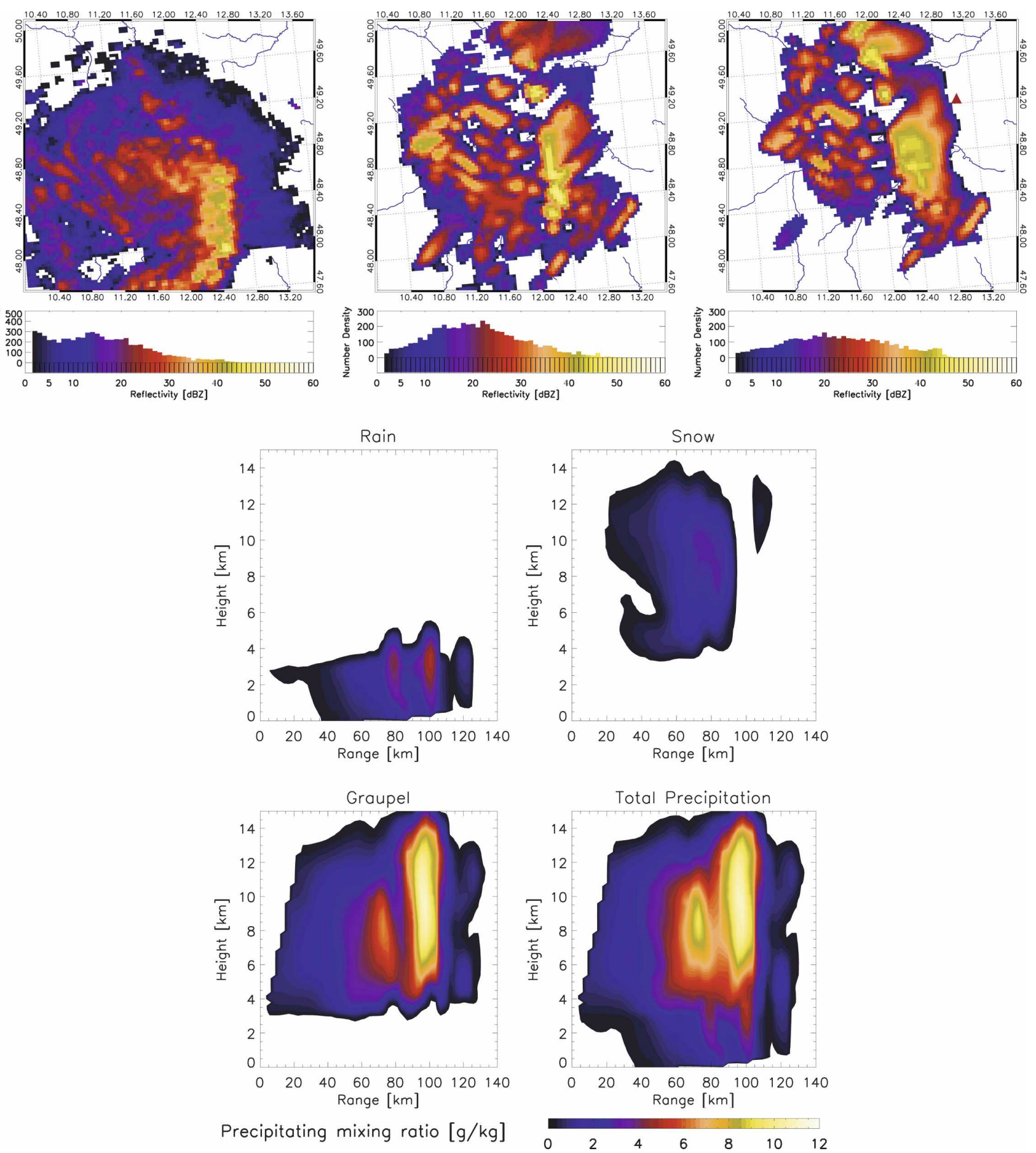

FIG. 9. (left) Observed and simulated $1^{\circ}$ PPI scan for 1900 UTC 12 Aug 2004. The simulations are shown for the different positions of the synthetic radar as marked by the red triangle: (middle) the actual position of the radar and (right) moved northeast to obtain the RHI scan with the largest correspondence to the observations. (bottom) Vertical cross sections of precipitation mixing ratios ( $\mathrm{g}$ $\mathrm{kg}^{-1}$ ) from the second radar position along a azimuth of $210^{\circ}$ as derived from a COSMO-DE forecast at 1900 UTC 12 Aug 2004 . Shown are precipitation mixing ratios for the single hydrometeor types and total precipitation.

the simulations, two PPI scans are shown resulting from different positions of the synthetic radar. While the first one shows the simulations for the actual position of the radar, the second position was chosen in order to obtain the RHI scan with the largest correspondence to the observations and this position will be used as the basis for the following discussion. Figure 8 also shows a vertical cross section of precipitation mixing ratio derived 
from the 1900 UTC forecast starting at the radar position with an azimuth angle of $210^{\circ}$. There are two cores of enhanced precipitation visible, especially in the mixing ratios of graupel and rain, and this vertical cross section is used as an input field for the polarimetric radar forward operator. In the first instance, the assumptions regarding the input parameters for the different hydrometeors are tested by simulating the polarimetric radar quantities for each hydrometeor type separately. Then, the synthetic polarimetric radar quantities for the entire precipitation field will be compared to observations by POLDIRAD.

Synthetic reflectivity, LDR, $Z_{\mathrm{DR}}$, and the hydrometeor classification derived from the polarimetric quantities are shown in Fig. 10 for each of the different precipitation types: rain, snow, and graupel. For rain, the two cores of heavy precipitation appear in all synthetic radar parameters reaching values of $55 \mathrm{dBZ}$ in reflectivity, $-25 \mathrm{~dB}$ in LDR, and more than $3 \mathrm{~dB}$ in $Z_{\mathrm{DR}}$. Within the convective cores of heavy precipitation, rain also exists above the melting layer because of the large updrafts in this part of the storm. The precipitation is mainly classified as light rain with some signatures of heavy rain in the region of the convective core due to enhanced values of $Z_{\mathrm{DR}}$. The rain existing above the $0^{\circ} \mathrm{C}$ isotherm is classified as snow, as the hydrometeor classification scheme only differentiates between rain and snow via the height of the melting layer.

The maximum mixing ratios of snow are significantly smaller than those of rain. Accordingly, the reflectivities in snow are also decreased while the reflectivities within the bright band are of the same order as the maxima in rain. For the polarimetric quantities, maximum values are found in the region of the bright band reaching values of $-15 \mathrm{~dB}$ in the case of LDR and 2.5 $\mathrm{dB}$ in the case of $Z_{\mathrm{DR}}$. In comparing the hydrometeor classification with the actual precipitation fields and the synthetic radar quantities, the precipitation is classified everywhere as snow apart from the region of the bright band, which is classified as graupel or wet hail because of the enhanced polarimetric quantities for melting snow. The remaining unclassified regions are due to the classification scheme failing to define parts of the $\mathrm{LDR}-Z_{\mathrm{DR}}$ space.

The synthetic reflectivities derived from the simulations considering only graupel reach intensities of 45 $\mathrm{dB} Z$. These are smaller than for rain although the graupel category produces the highest mixing rations of all hydrometeor types. This is due to the relatively small graupel density of $0.2 \mathrm{~g} \mathrm{~cm}^{-3}$ and the resulting small dielectric constant in the case of dry particles. For melting particles, the dielectric constant increases drastically explaining the reflectivities exceeding $50 \mathrm{dBZ}$ in the bright band. The polarimetric parameters show larger values than those for snow because of the larger dielectric constant and the different assumptions regarding axis ratio and canting angle. Within the melting layer, the values are comparable or slightly smaller. Accordingly, the precipitation is classified as graupel with signatures of heavier ice hydrometeors in the region of the bright band.

Figure 11 displays the synthetic radar quantities derived from the full precipitation field alongside the corresponding observations by POLDIRAD. The simulations are shown with and without attenuation effects to facilitate the discussion of the results. The observations show, as in the simulated precipitation field, a convective system with two convective cells and a stratiform region of precipitation. However, the simulated reflectivity fields look quite different. The convective core is mainly visible in the enhanced reflectivities in rain while the reflectivities in the ice phase are clearly underestimated. In the stratiform precipitation, reflectivities are overestimated in comparison to the observations. Furthermore, the synthetic reflectivities are dominated by an enhanced brightband signature in the stratiform precipitation. These differences are even larger for the simulation including attenuation effects as the extreme reflectivities within the bright band also cause major attenuation and, therefore, further reduce reflectivity in the convective core. Apart from the differences in reflectivity, the model overestimates the vertical extent of the storm and the height of the melting layer.

For the observations of $Z_{\mathrm{DR}}$, the maximum values are found in the regions with heavy rain and in the bright band because of the enhanced polarimetric signatures for melting snow. Behind the convective core, the observations are strongly attenuated reaching negative values of $Z_{\mathrm{DR}}$. The simulated $Z_{\mathrm{DR}}$ values when attenuation is included are of the same order as the observations for the regions with enhanced precipitation, while the values in the bright band are slightly overestimated.

In the observations, LDR clearly marks the bright band and the convective core with, in the latter case, enhanced values from the ground up to $9-\mathrm{km}$ height. These high values result from the presence of hail and graupel particles within the convection. The simulations are able to reproduce the observed values within the bright band. For the ice phase, the values are everywhere larger than observed by POLDIRAD, while the typical signatures of densely rimed ice particles within the convection are not reproduced. This can be expected since COSMO-DE does not include a representation of hail or high-density graupel. In the simu- 

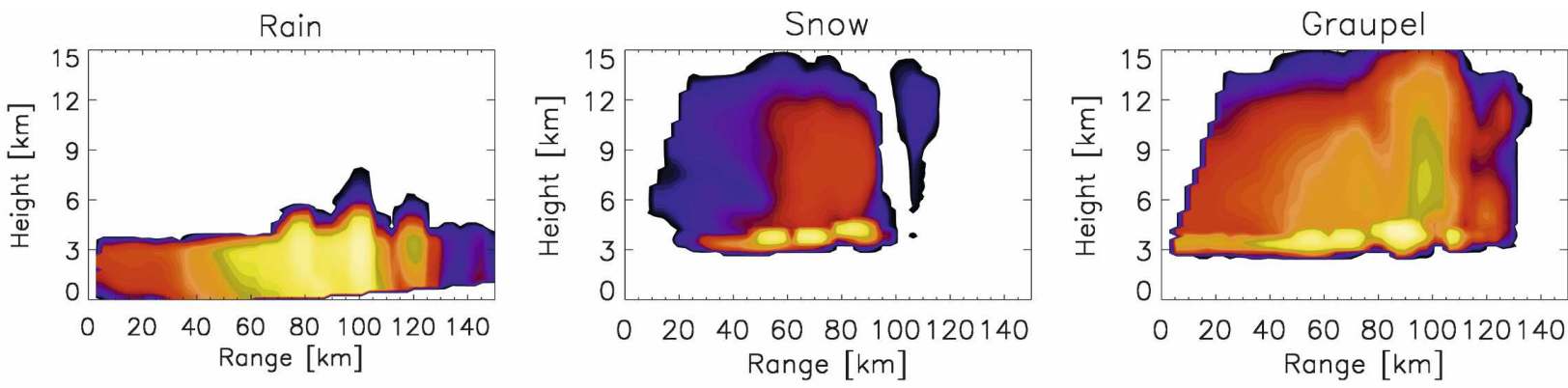

Reflectivity [dBZ]
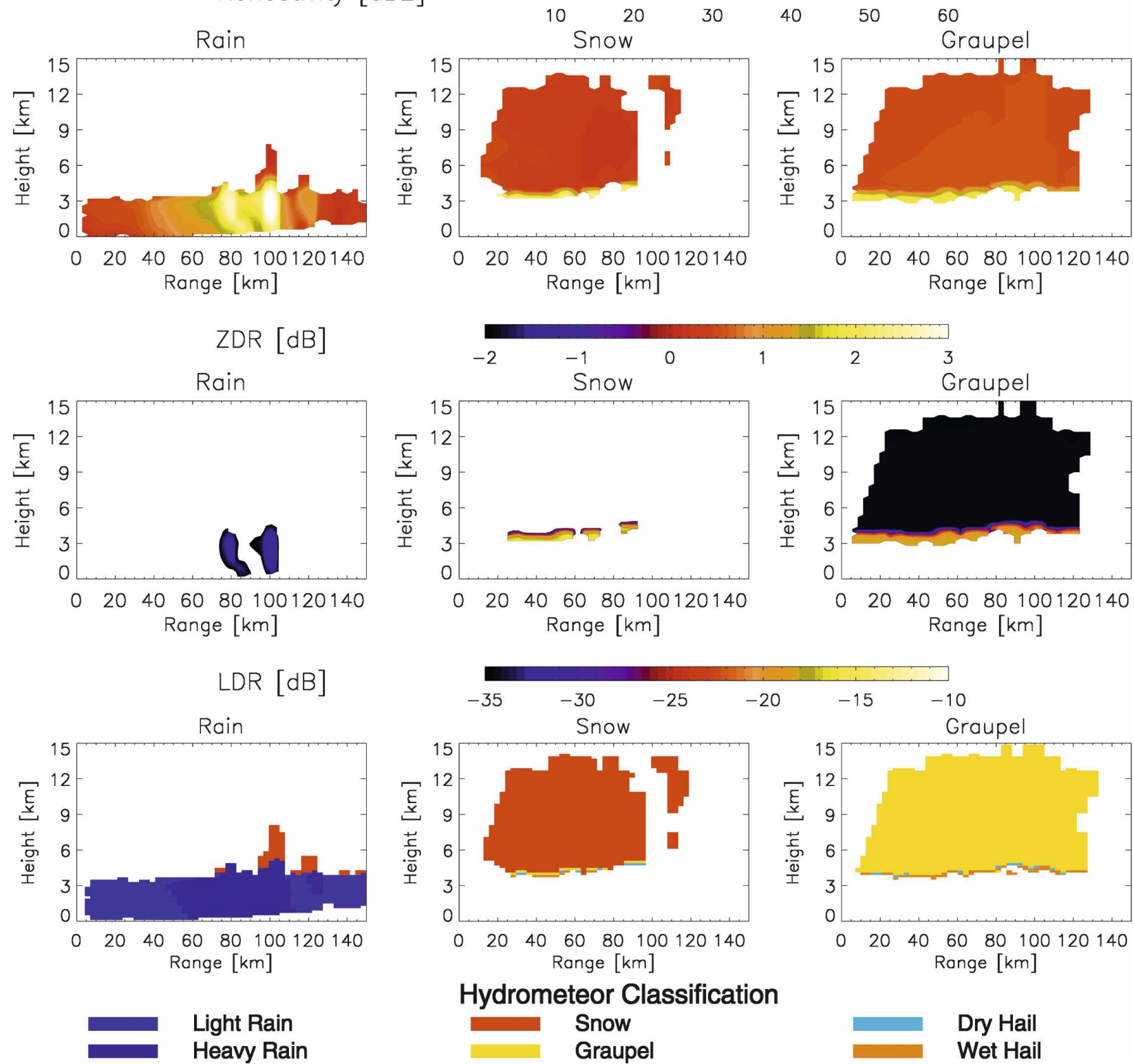

\section{Hydrometeor Classification}

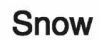

Graupel

FIG. 10. Synthetic RHI of reflectivity (dBZ), LDR (dB), $Z_{\mathrm{DR}}(\mathrm{dB})$, and the hydrometeor classification for the simulations only considering one hydrometeor type at the same time. Shown are the simulations for (left) rain, (middle) snow, and (right) graupel 

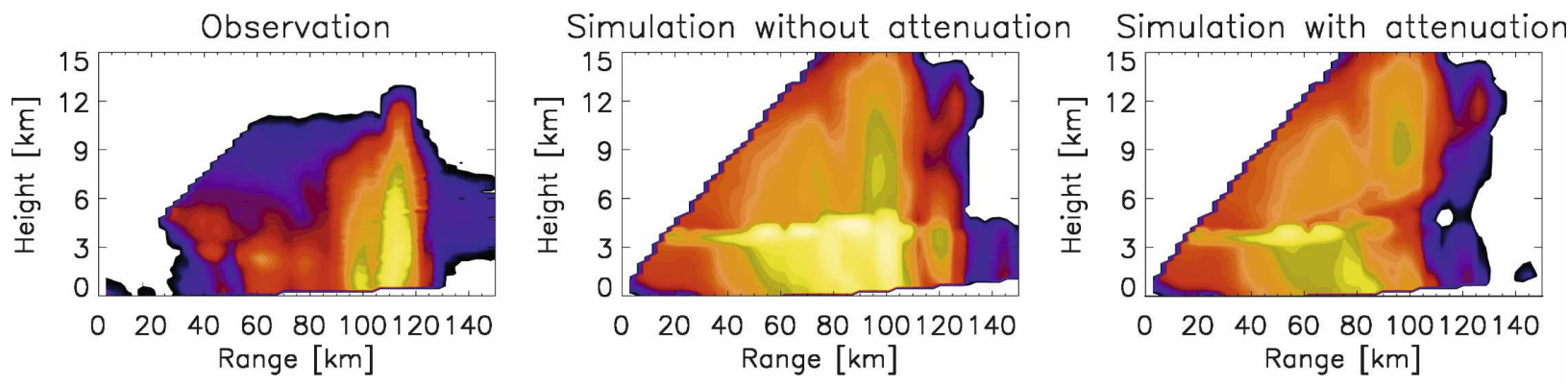

Reflectivity [dBZ]

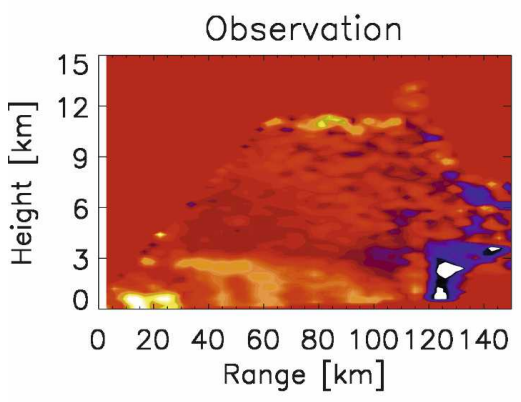

Simulation without attenuation Simulation with attenuation
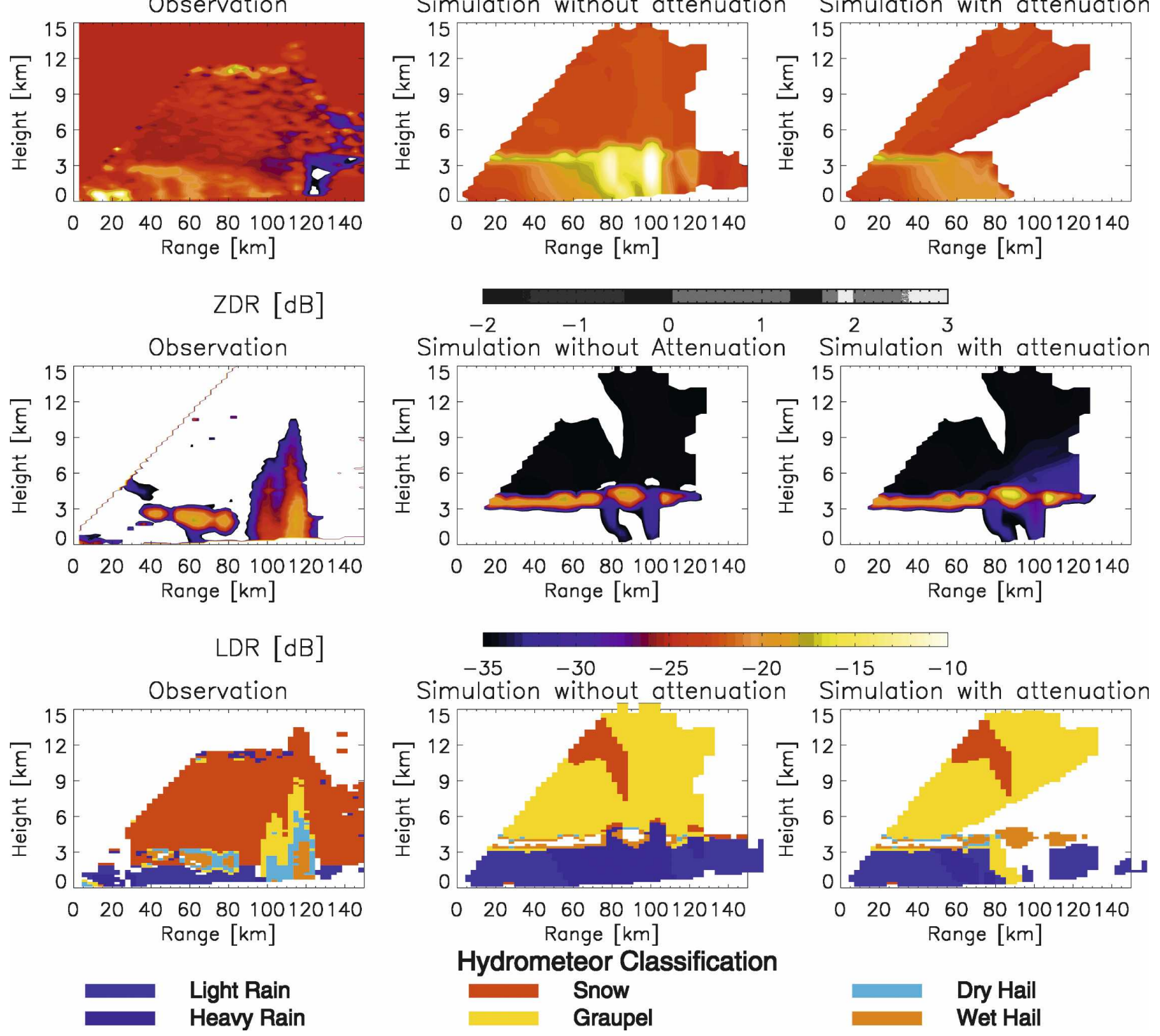

\section{Dry Hail \\ Wet Hail}

FIG. 11. (left) Observed and synthetic RHI of (top) reflectivity (dBZ), (second row) $Z_{\mathrm{DR}}$ (dB), (third row) LDR (dB), and the (bottom) hydrometeor classification on 1900 UTC 12 Aug 2004. The simulations are shown (middle) without and (right) with the consideration of attenuation effects. 
lations including attenuation, LDR values are increased because of the attenuation within the bright band and the convective core. Applying the hydrometeor classification to the observations, the convective core and the bright band are classified as a mixture of graupel and hail and can be clearly distinguished from the stratiform precipitation consisting of snow and rain. The hail and graupel signatures in the convective core extend from the ground to a height of $9 \mathrm{~km}$ and show that heavily rimed ice is present throughout the whole vertical extent of the convective core. In the simulations, the ice phase is dominated by graupel and almost no snow signature exists. This overestimation of the spatial distribution of graupel makes it impossible to distinguish the convective core in the ice phase from the hydrometeor classification. Major inconsistencies appear in the classification in regions affected by attenuation. The increased values of LDR in rain result in a misclassification of heavy rain as graupel. Furthermore, large parts of the precipitation above the melting layer are not classified because of missing definitions in the classification scheme. The comparison of the simulated and observed radar quantities shows that the model is not able to reproduce the storm's reflectivity or precipitation type. The latter point is true for the entire ice phase region, which consists mainly of graupel, in contrast to the larger portion of snow in the observations. Furthermore, in the model, no hail signatures exist within the convective core. This is consistent with the assumptions of COSMO-DE, which does not consider heavier ice hydrometeors.

\section{Discussion and conclusions}

The previous section demonstrated the consistency of the free parameters employed by SynPolRad with the assumptions of the mesoscale model regarding the microphysical properties of ice hydrometeors. For the simulations considering only one hydrometeor type, the synthetic polarimetric quantities together with the classification scheme reproduced everywhere the expected precipitation categories from the model, with the following exceptions. Misclassifications of rain and snow in strong updrafts occurred because of the assumptions of the classification scheme, which distinguishes between the two only by the height of the melting layer. In the region of the bright band, snow and graupel were classified as hail because of the increased polarimetric radar quantities resulting from melting ice hydrometeors and the corresponding increased dielectric constants. Attenuation effects on the polarimetric data and the hydrometeor classification were discussed, showing the possibility of producing signatures of highly rimed ice hydrometeors because of strongly attenuated and, therefore, enhanced LDR. Apart from these exceptions, the synthetic polarimetric radar quantities and the applied hydrometeor classification were consistent with the hydrometeor type given by the NWP model. This should occur because the free parameters were derived under the constraint that the resulting polarimetric quantities always range within the thresholds of the classification scheme, independent of the intensity of precipitation in the given hydrometeor class.

The specification of the free parameters, namely axis ratio and maximum canting angle, for each ice hydrometeor type was essential to bridge the gap between the information content of the microphysical parameterization scheme and the polarimetric quantities and to allow the application of SynPolRad to the forecasts in a model consistent way. The free parameters were derived employing three sets of information, namely the ice density from the NWP model, the typical thresholds for the polarimetric radar quantities from the hydrometeor classification, and the results from a sensitivity study. Additionally, it was assumed that the particles are dry and that the axis ratio does not vary with diameter. For the simulation of brightband signatures, the assumptions regarding the dielectric constant and the free parameters were changed in order to reproduce the typical LDR values of up to $-15 \mathrm{~dB}$.

The application of the polarimetric radar forward operator SynPolRad to the forecasts of a NWP model showed its ability to produce polarimetric quantities consistent with the model assumptions. The comparison with observations from the polarimetric Doppler radar (POLDIRAD) demonstrated the potential of the new method to evaluate not only the intensity of precipitation forecasts employing reflectivity but also the spatial distribution of hydrometeor types. Major differences between the observations and simulations were found, especially in the spatial distribution of ice phase hydrometeors. At present, SynPolRad computes the synthetic reflectivity, LDR, and $Z_{\mathrm{DR}}$ from predicted bulk water quantities and simulates the beam propagation in the model domain including refractivity and attenuation effects. In the future, polarimetric radar quantities related to propagation effects, such as the specific differential phase $K_{\mathrm{dp}}$, will also be considered. This is especially important as most of the planned polarimetric radar networks will use a hybrid polarization methodology, which will not allow observations of LDR. Effects due to beam broadening are not yet included in SynPolRad, but it may become important to consider these effects in the future. SynPolRad is easily adapted to other mesoscale models and microphysical parameterization schemes and has already been used 
on other mesoscale models (Gallus and Pfeifer 2008). Most important, the free parameters must be rederived following the model specifications. For microphysical parameterization schemes assuming wet or melting hydrometeor types such as hail, the free parameters can also be derived for a fixed particle water fraction, as has been done in the case of melting particles. Moreover, any formulation of the particle spectrum can be easily implemented into SynPolRad providing the means for testing and developing future microphysical parameterization schemes. This is especially important since polarimetric radar systems together with SynPolRad provide a unique method of evaluating details of microphysical parameterization schemes over large regions of space and time using routine measurements. This has the potential to significantly increase model skill, especially in the context of short-term forecasts of convective precipitation events, and could constitute a major step toward better quantitative precipitation forecasts.

Acknowledgments. The authors thank Prof. V. N. Bringi for providing the T-matrix code and G. Haase for providing the RadarSimulationsModell (RSM). This work was founded by the Deutsche Forschungsgemeinschaft (DFG) within the Priority Program SPP 1167 Quantitative Precipitation Forecast.

\section{REFERENCES}

Anagnostou, E. N., and W. F. Krajewski, 1997: Simulation of radar reflectivity fields: Algorithm formulation and evaluation. Water Resour. Res., 33, 1419-1428.

Andsager, K., K. V. Beard, and N. F. Laird, 1999: Laboratory measurements of axis ratios for large raindrops. J. Atmos. Sci., 56, 2673-2683.

Barber, P., and C. Yeh, 1975: Scattering of electromagnetic waves by arbitrarily shaped dielectric bodies. Appl. Opt., 14, 28642872.

Bechtold, P., and Coauthors, 2000: A GCSS model intercomparison for a tropical squall line observed during TOGACOARE. II: Intercomparison of single-column models and a cloud-resolving model. Quart. J. Roy. Meteor. Soc., 126, 865888.

Bohren, C. F., and L. J. Battan, 1982: Radar backscattering of microwaves by spongy ice spheres. J. Atmos. Sci., 39, 26232628.

Brandes, E. A., G. Zhang, and J. Sun, 2006: On the influence of assumed drop size distribution form on radar-retrieved thunderstorm microphysics. J. Appl. Meteor. Climatol., 45, 259268.

Bringi, V. N., and V. Chandrasekar, 2001: Polarimetric Doppler Weather Radar: Principles and Applications. Cambridge University Press, 636 pp.

_, R. M. Rasmussen, and J. Vivekanandan, 1986: Multiparameter radar measurements in Colorado convective storms. Part I: Graupel melting studies. J. Atmos. Sci., 43, 2545-2563.

Bryan, G. H., J. C. Wyngaard, and J. M. Fritsch, 2003: Resolution requirements for the simulation of deep moist convection. Mon. Wea. Rev., 131, 2394-2416.

Capsoni, C., M. D'Amico, and R. Nebuloni, 2001: A multiparameter polarimetric radar simulator. J. Atmos. Oceanic Technol., 18, 1799-1809.

Caumont, O., and Coauthors, 2006: A radar simulator for highresolution nonhydrostatic models. J. Atmos. Oceanic Technol., 23, 1049-1067.

Chandrasekar, V., W. A. Cooper, and V. N. Bringi, 1988: Axis ratios and oscillations of raindrops. J. Atmos. Sci., 45, 1323 1333.

Cheng, L., and M. English, 1983: A relationship between hailstone concentration and size. J. Atmos. Sci., 40, 204-213.

Chevallier, F., and P. Bauer, 2003: Model rain and clouds over oceans: Comparison with SSM/I observations. Mon. Wea. Rev., 131, 1240-1255.

Colle, B. A., M. F. Garvert, J. B. Wolfe, C. F. Mass, and C. P. Woods, 2005: The 13-14 December 2001 IMPROVE-2 event. Part III: Simulated microphysical budgets and sensitivity studies. J. Atmos. Sci., 62, 3535-3558.

Craig, G. C., and A. Dörnbrack, 2008: Entrainment in cumulus clouds: What resolution is cloud-resolving? J. Atmos. Sci., $\mathbf{6 5}$, 3978-3988.

Damrath, U., G. Doms, D. Fruhwald, E. Heise, B. Richter, and J. Steppeler, 2000: Operational quantitative precipitation forecasting at the German weather service. J. Hydrol., 239, 260 285.

Doviak, R. J., and D. S. Zrnic, 1984: Doppler Radar and Weather Observations. Academic Press, 458 pp.

— V. Bringi, A. Ryzhkov, A. Zahrai, and D. Zrnic, 2000: Considerations for polarimetric upgrades to operational WSR88D radars. J. Atmos. Oceanic Technol., 17, 257-278.

Droegemeier, K. K., J. D. Smith, S. Businger, and C. Doswell, 2000: Hydrological aspects of weather prediction and flood warnings: Report on the ninth prospectus development team of the U.S. Weather Research Program. Bull. Amer. Meteor. Soc., 81, 2665-2680.

Ducrocq, V., F. Bouttier, S. Malardel, T. Montmerle, and Y. Seity, 2005: Le Projet AROME. La Houille Blanche, 2, 39-43.

Ebert, E. E., U. Damrath, W. Wergen, and M. E. Baldwin, 2003: The WGNE assessment of short-term quantitative precipitation forecast. Bull. Amer. Meteor. Soc., 84, 481-492.

Fabry, F., and W. Szyrmer, 1999: Modeling of the melting layer: Part II: Electromagnetic. J. Atmos. Sci., 56, 3593-3600.

Ferrier, B. S., W. K. Tao, and J. Simpson, 1995: A double-moment multiple-phase four-class bulk ice scheme. Part II: Simulations of convective storms in different large-scale environments and comparisons with other bulk parameterizations. $J$. Atmos. Sci., 52, 1001-1033.

Friedrich, K., U. Germann, J. J. Gourley, and P. Tabary, 2007: Effects of radar beam shielding on rainfall estimation for polarimetric C-band radar. J. Atmos. Oceanic Technol., 24, 1839-1859.

Fritsch, J. M., and Coauthors, 1998: Quantitative precipitation forecasting: Report of the eighth prospectus development team, U.S. Weather Research Program. Bull. Amer. Meteor. Soc., 79, 285-299.

Fujiyoshi, Y., 1986: Melting snowflakes. J. Atmos. Sci., 43, $307-$ 311.

Gallus, W. A., Jr., and M. Pfeifer, 2008: Intercomparison of simulations using 5 WRF microphysical schemes with dualpolarization data for a German squall line. Adv. Geosci., 16, 109-116. 
Garvert, M. F., C. P. Woods, B. A. Colle, C. F. Mass, P. V. Hobbs, M. T. Stoelinga, and J. B. Wolfe, 2005: The 13-14 December 2001 IMPROVE-2 event. Part II: Comparison of MM5 model simulations of clouds and precipitation with observations. $J$. Atmos. Sci., 62, 3520-3534.

Gilmore, M. S., J. M. Straka, and E. N. Rasmussen, 2004: Precipitation uncertainty due to variations in precipitation particle parameters within a simple microphysics scheme. Mon. Wea. Rev., 132, 2610-2627.

Gourley, J. J., P. Tabary, and J. P. du Chatelet, 2006: Data quality of the Meteo France C-band polarimetric radar. J. Atmos. Oceanic Technol., 23, 1340-1356.

Guichard, F., and Coauthors, 2004: Modelling the diurnal cycle of deep precipitating convection over land with cloud-resolving models and single-column models. Quart. J. Roy. Meteor. Soc., 130, 3139-3172.

Haase, G., and S. Crewell, 2000: Simulation of radar reflectivities using a mesoscale weather forecast model. Water Resour. Res., 36, 2221-2231.

Heymsfield, A. J., 1978: The characteristics of graupel particles in northeastern Colorado cumulus congestus clouds. J. Atmos. Sci., 35, 284-295.

Höller, H., V. Bringi, J. Hubbert, M. Hagen, and P. F. Meischner, 1994: Life cycle and precipitation formation in a hybrid-type hailstorm revealed by polarimetric and Doppler radar measurements. J. Atmos. Sci., 51, 2500-2522.

Holt, A. R., 1984: The scattering of electromagnetic waves by single hydrometeors. Radio Sci., 17, 929-965.

Illingworth, A. J., 2004: Polarimetric measurements. Weather Radar: Principles and Advanced Applications, P. F. Meischner, Ed., Springer, 130-166.

- , and Coauthors, 2007: Cloudnet: Continuous evaluation of cloud profiles in seven operational models using groundbased observations. Bull. Amer. Meteor. Soc., 88, 883-898.

Keil, C., A. Tafferner, and H. Mannstein, 2003: Evaluating highresolution model forecasts of European winter storms by use of satellite and radar observations. Wea. Forecasting, 18, 732747.

Klaassen, W., 1988: Radar observations and simulations of the melting layer of precipitation. J. Atmos. Sci., 45, 3741-3753.

Liebe, H. J., G. A. Hufford, and M. G. Cotton, cited 1993: Propagation modeling of moist air and suspended water/ice particles at frequencies below $1000 \mathrm{GHz}$. Proc. AGARD 52nd Special Meeting of the Panel on Electromagnetic Wave Propagation, Palma de Mallorca, Spain, NATO, 208 pp. [Available online at http://www.rta.nato.int/Pubs/RDP.asp?RDP $=$ AGARD-CP-542.]

Matrosov, S. Y., R. F. Reinking, R. A. Kropfli, and B. W. Bartram, 1996: Estimation of ice hydrometeor types and shapes from radar polarization measurements. J. Atmos. Oceanic Technol., 13, 85-96.

Mishchenko, M. I., and L. D. Travis, 1998: Capabilities and limitations of a current Fortran implementation of the T-matrix method for randomly oriented, rotationally symmetric scatterers. J. Quant. Spectrosc. Radiat. Transfer, 60, 309-324.

Oguchi, T., 1983: Electromagnetic wave propagation and scattering in rain and other hydrometeors. Proc. IEEE, 71, 10291078.

Olson, W. S., P. Bauer, N. F. Viltard, D. E. Johnson, W.-K. Tao, R. Meneghini, and L. Liao, 2001: A melting-layer model for passive/active microwave remote sensing applications. Part I:
Model formulation and comparison with observations. $J$. Appl. Meteor., 40, 1145-1163.

Pfeifer, M., G. Craig, M. Hagen, and C. Keil, 2004: A polarimetric radar forward operator. Proc. Third European Conf. on Radar Meteorology (ERAD), Visby, Island of Gotland, Sweden, 494-498.

Pruppacher, H. R., and J. D. Klett, 2003: Microphysics of Clouds and Precipitation. Kluwer Academic Publishers, 954 pp.

Ray, P. S., 1972: Broadband complex refractive indices of ice and water. Appl. Opt., 11, 1836-1844.

Ryzhkov, A. V., T. J. Schuur, D. W. Burgess, P. L. Heinselman, S. E. Giangrande, and D. S. Zrnic, 2005: The joint polarization experiment: Polarimetric rainfall measurements and hydrometeor classification. Bull. Amer. Meteor. Soc., 86, 809824

Schroth, A. C., M. S. Chandra, and P. F. Meischner, 1988: A Cband coherent polarimetric radar for propagation and cloud physics research. J. Atmos. Oceanic Technol., 5, 804-822.

Skamarock, W. C., J. B. Klemp, J. Dudhia, D. O. Gill, D. M. Barker, W. Wang, and J. G. Powers, 2005: A description of the Advanced Research WRF version 2. NCAR Tech. Note NCAR/TN-468+STR, 88 pp.

Steppeler, J., G. Doms, U. Schattler, H. W. Bitzer, A. Gassmann, U. Damrath, and G. Gregoric, 2003: Meso-gamma scale forecasts using the nonhydrostatic model LM. Meteor. Atmos. Phys., 82, 75-96.

Straka, J. M., D. S. Zrnic, and A. V. Ryzhkov, 2000: Bulk hydrometeor classification and quantification using polarimetric radar data: Synthesis of relations. J. Appl. Meteor., 39, 13411372.

Szyrmer, W., and I. Zawadzki, 1999: Modeling of the melting layer. Part I: Dynamics and microphysics. J. Atmos. Sci., 56, 3573-3592.

Vivekanandan, J., 1986: Multiparameter radar measurements in Colorado convective storms. Ph.D. thesis, Colorado State University and NCAR, $196 \mathrm{pp}$.

, V. N. Bringi, and R. Raghavan, 1990: Multiparameter radar modeling and observation of melting ice. J. Atmos. Sci., 47, 549-564.

-, W. M. Adams, and V. N. Bringi, 1991: Rigorous approach to polarimetric radar modeling of hydrometeor orientation distributions. J. Appl. Meteor., 30, 1053-1063.

_, R. Raghavan, and V. N. Bringi, 1993: Polarimetric radar modeling of mixtures of precipitation particles. IEEE Trans. Geosci. Remote Sens., 31, 1017-1030.

— D. S. Zrnic, S. M. Ellis, R. Oye, A. V. Ryzhkov, and J. Straka, 1999: Cloud microphysics retrieval using S-band dualpolarization radar measurements. Bull. Amer. Meteor. Soc., 80, 381-388.

Warren, S. G., 1984: Optical constants of ice from the ultraviolet to the microwave. Appl. Opt., 23, 1206-1225.

Waterman, P. C., 1969: Scattering by dielectric obstacles. Alta Freq., 38, 348-352.

Zhang, G., J. Sun, and E. A. Brandes, 2006: Improving parameterization of rain microphysics with disdrometer and radar observations. J. Atmos. Sci., 63, 1273-1290.

Zrnic, D. S., T. D. Keenan, L. D. Carey, and P. May, 2000: Sensitivity analysis of polarimetric variables at a $5-\mathrm{cm}$ wavelength in rain. J. Appl. Meteor., 39, 1514-1526. , A. Ryzhkov, J. Straka, Y. Liu, and J. Vivekananadan, 2001: Testing a procedure for automatic classification of hydrometeor types. J. Atmos. Oceanic Technol., 18, 892-913. 